\title{
Feeding ecology and predation impact of the recently established amphipod, Themisto libellula, in the St. Lawrence marine system, Canada
}

\author{
Alexandra Marion ${ }^{1,2}$, Michel Harvey ${ }^{2, *}$, Denis Chabot ${ }^{3}$, Jean-Claude Brêthes ${ }^{1}$ \\ ${ }^{1}$ Institut des Sciences de la Mer (ISMER), Université du Québec à Rimouski (UQAR), 310 Allée des Ursulines, Rimouski, \\ Québec G5L 3A1, Canada \\ ${ }^{2}$ Direction des Sciences Océaniques et Environnementales, Ministère des Pêches et des Océans, \\ Institut Maurice-Lamontagne, CP 1000, Mont-Joli, Québec G5H 3Z4, Canada \\ ${ }^{3}$ Direction des Sciences Halieutique et de l'Aquaculture, Ministère des Pêches et des Océans, Institut Maurice-Lamontagne, \\ CP 1000, Mont-Joli, Québec G5H 3Z4, Canada
}

\begin{abstract}
Themisto libellula was virtually absent from the St. Lawrence marine system (SLMS) before 1990. Since then, it has become an abundant, full-time resident of this system. Hyperiid amphipods of the genus Themisto are principally carnivorous and represent an essential link in the trophic pathway from secondary production to higher trophic levels. Sampling of T. libellula was carried out in the lower St. Lawrence Estuary (LSLE) and the northwest Gulf of St. Lawrence (NWGSL) in the fall of 1998, 2003 and 2004 to study the feeding dynamics and predation impact of this species on mesozooplankton and macrozooplankton communities. Our results showed that T. libellula was an opportunistic predator with a circadian feeding cycle; activity was higher during the second part of the night and the sunrise period. Stomach content analyses showed that these amphipods consumed chiefly copepods, in particular, the copepodite stages CIV and CV of Calanus finmarchicus. Euphausiids, chaetognaths, amphipods and mysids constituted other important prey. Digestion time was estimated at $13 \mathrm{~h}$. The daily ingestion rate of $T$. libellula was estimated using 2 approaches: (1) stomach fullness index and (2) mean number of prey removed per unit of time and converted to prey biomass using the stage-species dry masses of each prey item. We found that the daily ingestion rate of T. libellula ranged from 6.32 to $16.82 \%$ of body dry mass per day in both study areas (LSLE and NWGSL). Concerning predation impact, T. libellula consumed between 0.14 and $1.79 \%$ of the combined mesozooplankton and macrozooplankton standing stock per day and between 0.43 and $2.48 \%$ of the C. finmarchicus standing stock. Themisto libellula may thus exert a significant control on the mesozooplankton and macrozooplankton communities in the SLMS through direct predation.
\end{abstract}

KEY WORDS: Hyperiid amphipod $\cdot$ Themisto libellula $\cdot$ Feeding ecology $\cdot$ Ingestion rate $\cdot$ Digestion time $\cdot$ Predation impact $\cdot$ Gulf of St. Lawrence

\section{INTRODUCTION}

Hyperiid amphipods of the genus Themisto are principally carnivorous (Kane 1963, Sheader \& Evans 1975, Falk-Petersen et al. 1987) and mainly feed on a large variety of mesozooplankton such as calanoid copepods, euphausiids, and chaetognaths (Pakhomov \& Perissinotto 1996, Froneman et al. 2000, Auel et al. 2002). Reciprocally, they are an important source of food for fishes (Dempson et al. 2002), seabirds (Pedersen \& Falk 2001), seals (Nielssen et al. 1995) and whales (Lowry \& Frost 1984) in arctic regions. Thus, they represent an essential component of the trophic pathways from the secondary production of mesozooplankton to higher trophic levels.

Themisto libellula (Lichtenstein, 1822) is the largest species of its genus. It is widely distributed and abundant in the ice-covered central Arctic Ocean and most 
of the adjacent European and North American arctic seas (see reviews in Dunbar 1957, Percy \& Fife 1993, Dalpadado et al. 2001, Auel \& Werner 2003). In this context, T. libellula is recognized as a typical arctic species that can be regarded as a good indicator of the presence of arctic waters in different subarctic regions (Dunbar 1957, Dalpadado et al. 2001). The few available studies on the biology of $T$. libellula have dealt with its distribution, reproductive behaviour, and life cycle in the Canadian Arctic (Dunbar 1957, Percy 1993a,b) and the Barents, Greenland, and Norwegian seas (Koszteyn et al. 1995, Dalpadado et al. 2001, Dalpadado 2002).

This species is often present in high abundance and is bound to play an important role in transferring energy from smaller planktonic organisms to fish, birds and marine mammals, but its feeding ecology remains virtually unknown. Fortier et al. (2001) examined the daily variation in feeding intensity and diet composition of Themisto libellula in the under-ice surface layer during the midnight sun period in the arctic Barrow Strait, and Auel \& Werner (2003) estimated the daily ingestion rates of $T$. libellula in the marginal ice zone of the arctic Fram Strait by feeding experiments, respiration measurements and an allometric approach based on body mass.

The purpose of the present study was to provide estimates of the diet composition, diel feeding behaviour, digestion time, daily ration and predation impact of Themisto libellula on the zooplankton standing stock in the Gulf of St. Lawrence (GSL) and the lower St. Lawrence Estuary (LSLE), which together form the St. Lawrence marine system (SLMS). This knowledge is particularly important considering that $T$. libellula was virtually absent from this area before the 1990s except for the occasional presence of a few juveniles near the Strait of Belle Isle (Bousfield 1951, Huntsman et al. 1954, Hoffer 1971). It has now become an abundant, full-time resident of the SLMS, with an annual mean \pm SD abundance varying between $0.17 \pm 0.33$ and $16.50 \pm 13.33$ ind. $\mathrm{m}^{-2}$ in the LSLE and the northwest GSL (NWGSL) (1994 to 2005), respectively (Harvey et al. 2005). In this study we show that $T$. libellula is indeed an important predator for many species of copepods, euphausiids and chaetognaths, extending the knowledge on the St. Lawrence marine trophic ecosystem structure.

\section{MATERIALS AND METHODS}

Field sampling. The present study is based on samples of hyperiid amphipods collected during the annual macrozooplankton monitoring survey carried out in the LSLE and the NWGSL since 1994 by the
Maurice-Lamontagne Institute, Fisheries and Oceans Canada (Harvey et al. 2005). This survey was conducted in early September from 1994 to 2003 and in early November in 2004 and 2005. Zooplankton were sampled at 44 stations (26 stations in the LSLE and 18 in the NWGSL) distributed along 8 transects from Les Escoumins to Sept-îles (Fig. 1A) using a $1 \mathrm{~m}^{2}$ BIONESS sampler equipped with 9 opening/closing nets (333 $\mu \mathrm{m}$ mesh). In 2003 an additional 19 stations located between transects were sampled. The duration of the surveys varied between 3 and $5 \mathrm{~d}$. For the present study, a subset of the available stations was sampled to obtain a good coverage of the $24 \mathrm{~h}$ cycle, regardless of the date of sampling. Approximately half the stations were sampled during daytime and half during nighttime. The BIONESS was first deployed to ca. $5 \mathrm{~m}$ off the bottom with the nets closed and then towed obliquely toward the surface with the ship traveling at ca. 2 to 3 knots. Depending on station depth, 1 or 2 depth strata were sampled: 0 to $150 \mathrm{~m}$ and $150 \mathrm{~m}$ to the bottom for stations deeper than $150 \mathrm{~m}$, and $0 \mathrm{~m}$ to the bottom for shallower stations. At each station, the water column was sampled twice using 4 (for depths > $150 \mathrm{~m}$ ) or 2 (for depths $<150 \mathrm{~m}$ ) different nets. Total water volume filtered in each stratum was estimated using an electronic flowmeter (General Oceanics model 2031H) installed in the mouth of each net of the BIONESS sampler. At the end of each BIONESS tow, nets were rinsed and the cod-end contents were preserved in $4 \%$ buffered formaldehyde within $10 \mathrm{~min}$ of the end of the tow.

In the laboratory, all macrozooplankton categories from all samples, including adult and juvenile euphausiids, mysids, hyperiid amphipods, chaetognaths and jellyfishes, were sorted, identified, counted and weighed (wet mass). Moreover, the total biomass (wet mass) of mesozooplankton, predominantly composed of copepods, was determined for each sample.

Stomach content analysis. To describe the diet and the diurnal cycle in feeding of Themisto libellula, specimens sampled in fall 1998, 2003 and 2004 in each region (LSLE and NWGSL) were examined (Fig. 1B). These years were selected because of the high abundance of T. libellula (between 11 and 18 ind. $\mathrm{m}^{-2}$ ) (Harvey et al. 2005). Stomach content analyses were more detailed for organisms sampled in 2003 than in 1998 and 2004 because of time considerations. To obtain a good coverage of the $24 \mathrm{~h}$ cycle, 9 and 8 stations were chosen during each year in the LSLE and the NWGSL, respectively, with samples taken at intervals of ca. $3 \mathrm{~h}$ in each region (Table 1). In each region 3 to $5 \mathrm{~d}$ of data were combined to obtain sufficient coverage of the daily cycle.

In 2003, between 10 and 20 ind. were randomly selected from each sampling interval and examined for 


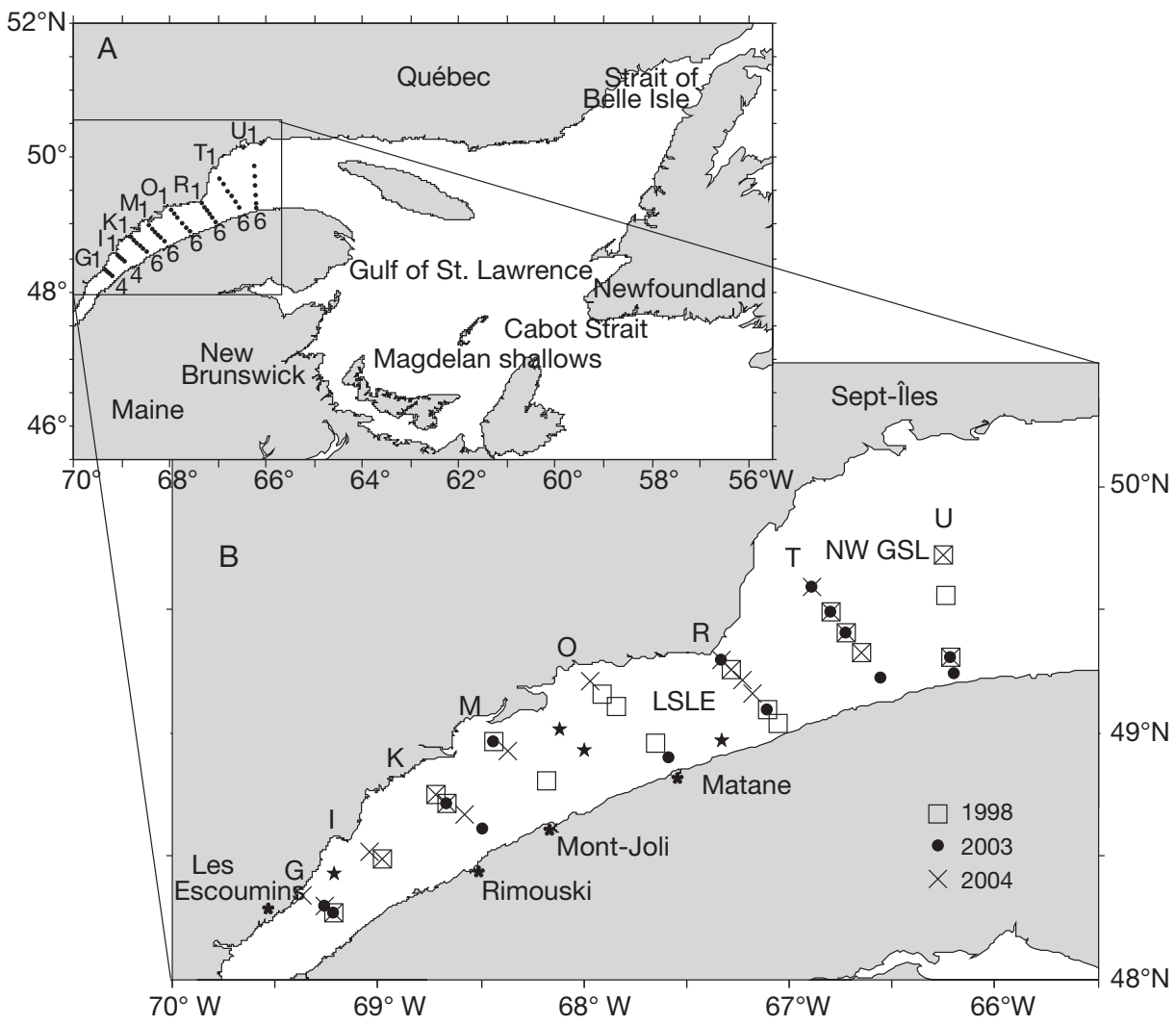

Fig. 1. (A) Location of sampling stations during the annual macrozooplankton biomass survey carried out in the lower St. Lawrence Estuary (LSLE; transects G to O) and the northwest Gulf of St. Lawrence (NWGSL; transects R to U) from 1994 to 2005. The stations are numbered from 1 (north shore) to 4 or 6 (south shore). (B) Stations sampled in 1998, 2003 and 2004 for the stomach content analysis of Themisto libellula including the additional stations located between transects sampled in 2003 ( $\star$ )

Table 1. Themisto libellula. Stations selected from the lower St. Lawrence Estuary (LSLE) and northwest Gulf of St. Lawrence (NWGSL) surveys in fall 1998, 2003 and 2004 to cover the $24 \mathrm{~h}$ period with gaps of 2 to $3 \mathrm{~h}$, whenever possible. Stations are sorted by time of sampling, not by date. Time is Eastern Daylight Time in September and Eastern Standard Time in November. Daytime shown in italics, periods of sunset and sunrise in grey and nighttime in bold. TOD = time of day, Stn $=$ station, nd $=$ no data

\begin{tabular}{|c|c|c|c|c|c|c|c|c|c|}
\hline \multirow{2}{*}{ Sampling zone } & \multicolumn{3}{|c|}{$-1998 \longleftarrow$} & \multicolumn{3}{|c|}{$2003 \longleftarrow$} & \multirow[b]{2}{*}{ TOD $(\mathrm{h})$} & \multirow{2}{*}{$\begin{array}{r}-2004 \\
\text { Date }\end{array}$} & \multirow[b]{2}{*}{ Stn } \\
\hline & TOD (h) & Date & Stn & TOD $(\mathrm{h})$ & Date & Stn & & & \\
\hline \multirow[t]{9}{*}{ LSLE } & 00:30 & $13 \mathrm{Sep}$ & M1 & 01:29 & 14 Sep & H1 & 00:46 & 10 Nov & G4 \\
\hline & 03:15 & 12 Sep & I3 & 03:52 & 13 Sep & K4 & 01:40 & $10 \mathrm{Nov}$ & G3 \\
\hline & $06: 30$ & $17 \mathrm{Sep}$ & O5 & $05: 12$ & 14 Sep & G4 & 03:22 & $10 \mathrm{Nov}$ & G1 \\
\hline & $09: 40$ & $13 \mathrm{Sep}$ & M5 & $07: 14$ & 14 Sep & G3 & 06:07 & $10 \mathrm{Nov}$ & $\mathrm{I} 2, \mathrm{I} 3$ \\
\hline & $12: 55$ & $12 \mathrm{Sep}$ & $K 4$ & $11: 50$ & 11 Sep & P6 & 09:41 & $10 \mathrm{Nov}$ & K3 \\
\hline & $15: 00$ & $12 \mathrm{Sep}$ & K3 & $14: 36$ & $12 \mathrm{Sep}$ & M1 & $13: 00$ & $10 \mathrm{Nov}$ & $K 4$ \\
\hline & $18: 00$ & 11 Sep & G4 & $17: 44$ & 08 Sep & O6 & $15: 00$ & $10 \mathrm{Nov}$ & K5 \\
\hline & 22:00 & 13 Sep & O3 & $21: 17$ & $13 \mathrm{Sep}$ & K6 & $18: 30$ & $10 \mathrm{Nov}$ & M2 \\
\hline & 23:40 & 13 Sep & O2 & $23: 47$ & 11 Sep & N1 & $22: 38$ & 11 Nov & 01 \\
\hline \multirow[t]{9}{*}{ NWGSL } & 03:30 & 15 Sep & T2 & 00:04 & 09 Sep & U6 & 01:40 & 11 Nov & U6 \\
\hline & 06:30 & 14 Sep & $\mathrm{R} 2$ & 02:09 & 09 Sep & U5 & nd & $11 \mathrm{NoV}$ & nd \\
\hline & 09:40 & $16 \mathrm{Sep}$ & U5 & $05: 12$ & 11 Sep & $\mathrm{R} 1$ & 09:51 & $11 \mathrm{Nov}$ & U2 \\
\hline & $11: 25$ & 15 Sep & $U 2$ & 09:55 & $10 \mathrm{Sep}$ & T3 & $12: 49$ & $11 \mathrm{Nov}$ & $R 4$ \\
\hline & $14: 00$ & $14 \mathrm{Sep}$ & $R 5$ & $11: 45$ & $10 \mathrm{Sep}$ & $T 4$ & $14: 53$ & $11 \mathrm{NoV}$ & $R 3$ \\
\hline & $15: 55$ & 14 Sep & $R 6$ & $15: 00$ & $10 \mathrm{Sep}$ & T5 & $15: 43$ & $11 \mathrm{NoV}$ & $R 2$ \\
\hline & $19: 00$ & 15 Sep & T3 & $21: 30$ & 10 Sep & R5 & $16: 40$ & $11 \mathrm{NoV}$ & $R 1$ \\
\hline & $22: 50$ & 15 Sep & U3, T4 & 23:46 & 09 Sep & T1 & $20: 27$ & $11 \mathrm{NoV}$ & $T 4, T 5$ \\
\hline & & & & & & & $22: 30$ & $11 \mathrm{Nov}$ & T2, T3 \\
\hline
\end{tabular}


stomach contents. A total of 110 and 96 ind. were analyzed in the LSLE and the NWGSL, respectively. First, total length was measured from the front of the head to the tip of the longest uropod (Dunbar 1957) using a stereomicroscope connected to the Pro Plus image analysis software. After measurements, each individual was blotted dry on filter paper and its wet mass determined to the nearest $0.1 \mathrm{mg}$. The digestive tract, excluding the mouth and the pharynx, was removed from each individual under a stereoscopic microscope, opened, and the contents spread on a glass slide. After the stomach contents were removed, each individual was placed in an oven-dried, pre-weighed aluminum cup, dried at $60^{\circ} \mathrm{C}$ in an oven for $24 \mathrm{~h}$ and then weighed with a Mettler MT5 balance $( \pm 0.001 \mathrm{mg})$.

The digestion index (DI) of the stomach contents was estimated and assigned to one of the following categories. Stage I indicated no evidence of digestion; at this stage, prey identification was easy. At Stage II, digestion had just started and prey were intact except for the most delicate parts. When prey were moderately digested and clearly affected by digestion, it was classified as Stage III. Stage IV was assigned when digestion was well advanced. Prey were highly fragmented and prey identification was difficult. Finally, at Stage V, digestion was almost complete and prey were unidentifiable.

After estimating the stage of digestion, prey were counted and identified to the lowest possible taxonomic level. Prey items were divided into 8 taxonomic categories: amphipods, chaetognaths, Calanus spp. (including the copepodid stages), other copepods, euphausiids, isopods, mysids and other items. In cases where we found only fragments of copepods such as prosomes and/or urosomes, they were counted separately and fragment type with the highest number was assumed to represent the number of prey. After prey identification, dry mass of the stomach contents of each amphipod was determined with the same method used for body dry mass. Finally, the stomach fullness index (SFI) as percentage of body dry mass was calculated by dividing the dry mass of the stomach contents by the dry mass of the amphipod body $\times 100$ (Pakhomov \& Perissinotto 1996).

For 1998 and 2004, we only estimated total length, body wet mass and SFI. Spatial variation of the SFI was estimated in 2 series of 10 ind. sampled at the same hour at 2 different stations, during 3 different periods of the day in each region (LSLE and NWGSL) in fall 2004. These periods of the day were selected according to the availability of stations sampled at the same hour.

Stomach content regurgitation and cod-end feeding were not regarded as important in this study since prey in the mouth and the pharynx were not taken into account in the data analysis. Concerning cod-end feeding, similar to what Sameoto (1988) found for the lantern fish Benthosema glaciale sampled with the BIONESS at 2 to 3 knots, most amphipods were dead or dying when captured even though their physical appearance was still very good. Sameoto (1988) suggested that the speed of the tow meant that the large amphipods were forced against the mesh of the net and it is unlikely that they would be able to feed under these circumstances.

Data analysis. The numbers of Themisto libellula collected in the different depth strata were integrated over the entire water column to obtain the number of individuals per $\mathrm{m}^{2}$. The length-frequency distributions of T. libellula sampled in the LSLE and the NWGSL in 1998, 2003 and 2004 were examined graphically and the relationships between wet mass and total length were compared between regions and years using ANCOVA on log-transformed data.

Spatial variability of the SFI was analyzed by comparing the mean SFI estimated for 2 series of 10 ind. sampled at the same hour at 2 different stations during 3 different periods of the day in each region (LSLE and NWGSL), with a Student's $t$-test on log-transformed data.

The diel variation of the SFI was first examined graphically in individuals sampled every $3 \mathrm{~h}$ during a $24 \mathrm{~h}$ period in each region (LSLE and NWGSL) in the fall of 1998, 2003 and 2004. Thereafter, the data were regrouped (regions and years) and the diel variation of the SFI was tested statistically using generalized additive models (GAMs) using the R software (R Development Core Team 2006) and MGCV package (Wood 2005). GAMs are an extension of generalized linear models in which relationships between the dependent and independent variables are not constrained to particular parametric forms. Instead, explanatory terms are modelled non-parametrically using a scatterplot smoother. The effect of time of day was modelled using a cubic spline function. Statistical significance was assessed using the Fisher test (see Darbyson et al. 2003). The same analyses were done using the DI estimated for individuals sampled in the LSLE and the NWGSL in fall 2003.

Results from stomach content analyses were expressed as the number of prey items per individual Themisto libellula. The biomass of prey $i\left(\mathrm{BP}_{i}\right)$ in a stomach was obtained by multiplying the average number of that prey type by its estimated dry mass from the copepod stage-species dry masses table produced by the Atlantic Zone Monitoring Program (AZMP) (Fisheries and Oceans Canada unpubl. data). This table includes the stage-species dry masses of several copepod species found at different times of the year along the Canadian Atlantic coast, including the 
Gulf of St. Lawrence. In addition, the dry masses of the other prey categories found in T. libellula stomachs (amphipods, chaetognaths, euphausiids, isopods, mysids) were obtained locally from different research projects (Harvey et al. 2008).

The daily ingestion rates (DIR) of Themisto libellula were estimated using 2 approaches, (1) the SFI and (2) the mean number of prey removed per unit of time and converted to prey biomass using the stage-species dry masses of each prey item. The SFI approach was that of Pakhomov \& Perissinotto (1996) and Froneman et al. (2000):

$$
\mathrm{DIR}_{1}=G \times 24 \times \mathrm{DT}^{-1}
$$

where $G$ is the average value of the $24 \mathrm{~h}$ integrated (circadian cycle) SFI in percent body dry mass and DT is the digestion time in hours (Bajkov 1935). The digestion time was evaluated by calculating the difference between the time of the day when the highest values of SFI and DI, obtained by GAMs, were observed.

The second approach was based on the stomach content analyses from individuals sampled in the LSLE and the NWGSL in fall 2003. In this approach, we first estimated the feeding rates (FR) of each individual $j$ using the following equation:

$$
\mathrm{FR}_{j}=\sum_{i=1}^{\mathrm{n}} \mathrm{BP}_{i} \times 100 \times \mathrm{Tlib}_{j D M}{ }^{-1}
$$

where $\mathrm{BP}_{i}$ is the biomass of prey $i$ in the stomach of amphipod $j, T l i b_{j D M}$ is the dry mass (DM, without the stomach content) of Themisto libellula individual $j$, and $\mathrm{n}$ is the number of prey analysed in each stomach. FR was thereafter estimated for each time period $(p)$ using the following equation:

$$
\mathrm{FR}=\sum_{p=1}^{\mathrm{k}}\left(\sum_{j=1}^{\mathrm{m}} \mathrm{FR}_{j} \times \mathrm{m}^{-1}\right) \times \mathrm{k}^{-1}
$$

where $\mathrm{m}$ is the number of amphipods analysed during each time period, including empty stomachs, and $\mathrm{k}$ is the number of time periods analysed during each $24 \mathrm{~h}$ period. This calculation was repeated for each region. Daily ingestion rates $\left(\mathrm{DIR}_{2}\right)$ were then calculated as:

$$
\mathrm{DIR}_{2}=\mathrm{FR} \times 24 \times \mathrm{DT}^{-1}
$$

where DT is the digestion time in hours. This second method made it possible to calculate feeding rate and daily ingestion rate for specific prey items.

To estimate the predation impact of Themisto libellula on the zooplankton standing stock, the daily ingestion rates were multiplied by the biomass of T. libellula at each station (see Froneman et al. 2000). This was then expressed as (1) a percentage of total zooplankton biomass at each station, evaluated during the annual macrozooplankton biomass monitoring survey (two estimates, using $\mathrm{DIR}_{1}$ and $\mathrm{DIR}_{2}$ ), and (2) a per- centage of total biomass of the most abundant copepod species found in the amphipod stomach contents, including the copepodid stages of Calanus finmarchicus (using $\mathrm{DIR}_{i}$ ). The mean abundance and biomass of the different copepod species were estimated from the AZMP zooplankton data collected in fall 2003 along 2 sections located in the LSLE and the NWGSL, respectively (Harvey et al. 2004) and the AZMP copepod stage-species dry mass table.

\section{RESULTS}

\section{Size distribution of Themisto libellula}

The length-frequency distributions of Themisto libellula sampled in the LSLE and the NWGSL in the fall of 1998, 2003 and 2004 show that the median values of the smaller and the larger size classes were similar between regions during each year, but were lower in 1998 (30 and $42 \mathrm{~mm}$, respectively) than in 2003 (33 and $42 \mathrm{~mm}$ ) and 2004 (36 and $45 \mathrm{~mm}$ ) in both regions (Fig. 2). The relative occurrence of the smaller and the
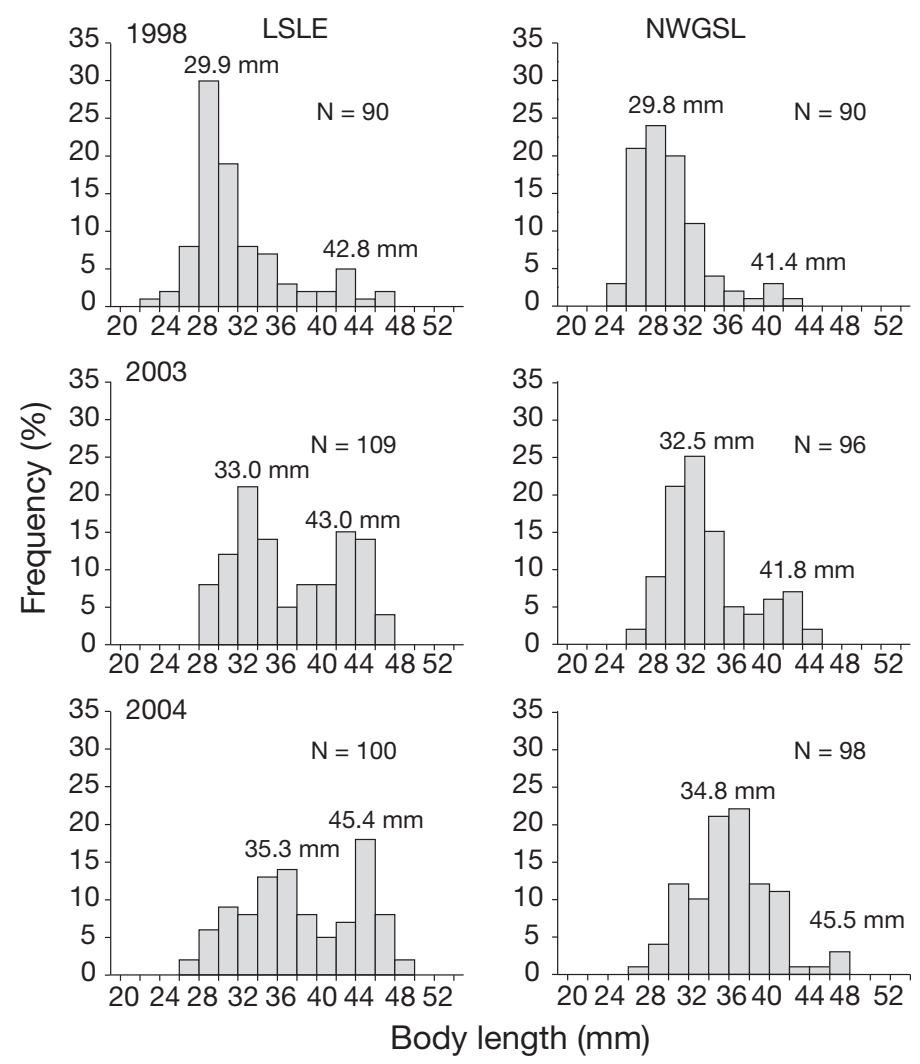

Fig. 2. Themisto libellula. Length-frequency distributions of individuals used for the stomach content analysis in the LSLE and the NWGSL in 1998, 2003 and 2004. N = total number of individuals measured. The median is indicated as a number above each size class 


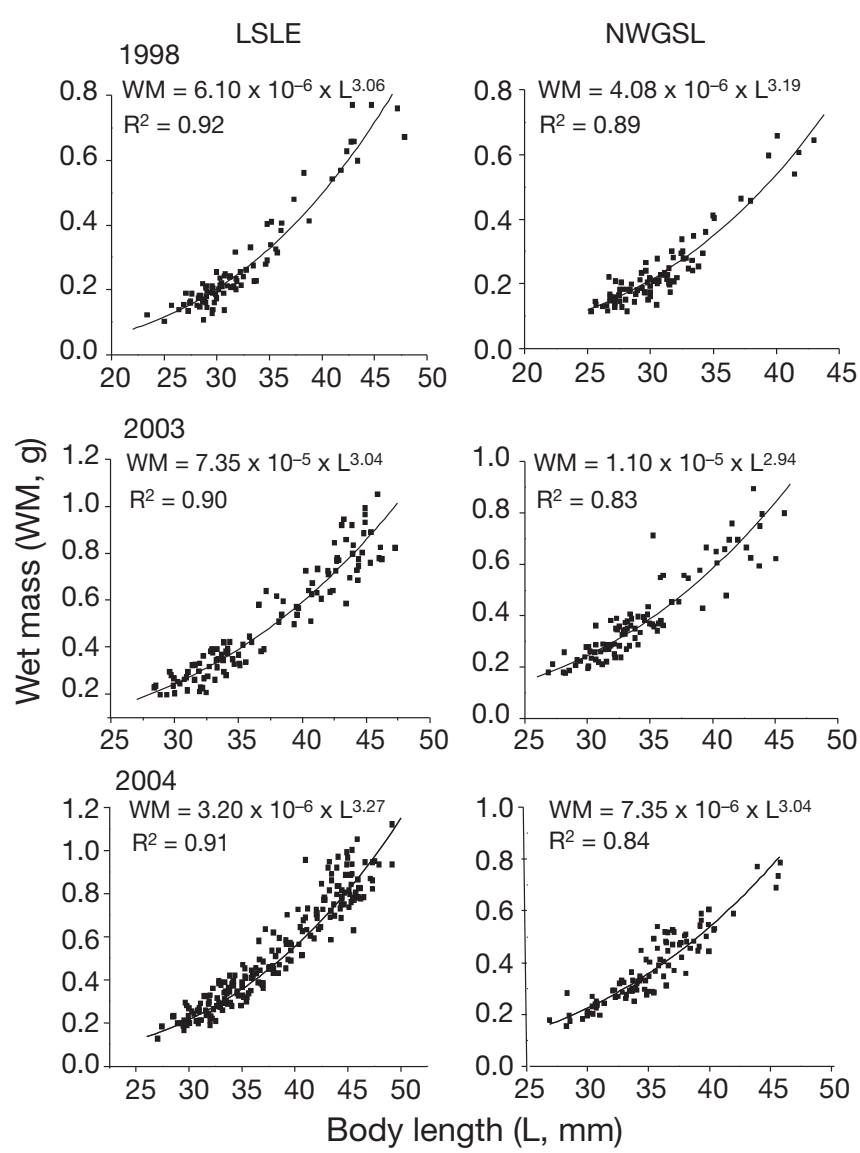

Fig. 3. Themisto libellula. Total body length relationships of individuals used for the stomach content analysis in the LSLE and the NWGSL in 1998, 2003 and 2004

larger size classes varied between 80 and $94 \%$ and 20 and $6 \%$, respectively, during each year in both regions, except in the LSLE in 2003 and 2004 where the relative occurrence of the smaller and larger size classes varied between approximately 40 and $60 \%$, respectively. The similarity in the median values of both size classes between areas within year and differences between years were tested statistically by comparing the regressions between total body wet mass and total length between regions and years (Fig. 3). Results of the ANCOVA showed no significant effect of the sampling zone, a significant effect of the year and no significant interaction between factors (Table 2).

\section{Spatial feeding pattern}

The mean SFI was estimated in 2 series of 10 ind. sampled at the same hour at 2 different stations, during 3 different periods of the day in each region (LSLE and NWGSL) in fall 2004 (Fig. 4). Based on the results of the Student's $t$-test, there was no spatial variation of the mean SFI during the 3 periods of the day in both regions (Fig. 4). This result supports the hypothesis that there was no spatial variation of the circadian feeding cycle within each of the sampled regions.

\section{Diel feeding pattern}

In fall 2003 when temporal coverage was best, there was a significant diel pattern for SFI in both regions (Fig. 5). The mean values of SFI ranged from 3.21 to $4.67 \%$ in the LSLE and from 2.18 to $5.65 \%$ in the NWGSL (Fig. 5). Mean SFI varied significantly between day and night periods in both regions (LSLE: $t_{(7)}=-3.918, \mathrm{p}=0.006$; NWGSL: $t_{(5.9)}=-2.801, \mathrm{p}=$ 0.032). The highest value of SFI was found during the sunrise period between 05:00 and 07:00 $\mathrm{h}$ in the morning. This was followed by a sharp diurnal decrease and the lowest SFI value was observed at around noon in both regions (Fig. 5). Thereafter, SFI stayed at a low level during the afternoon and the evening periods and increased again during the night.

Likewise, there was a significant diel pattern of variation of the DI in the LSLE and the NWGSL in fall 2003 (Fig. 5). In both regions, the lowest DI value was observed during the sunrise period, at the same period as the maximum SFI value. Thereafter, a sharp diurnal increase led to the highest DI value, observed during the afternoon in the LSLE and around noon in the NWGSL (Fig. 5). The maximum and the minimum values of the SFI and the DI observed during the sunrise period in both regions support the hypothesis that Themisto libellula consumes most of their prey during the second part of the night. The same daily pattern of SFI variation, showing higher values during the period of darkness followed by a sharp diurnal decrease and the lowest value during the daylight period, was also observed in fall 1998 in the LSLE (Fig. 6). However, this daily pattern of variation of the SFI was not apparent in the NWGSL in fall 1998 or fall 2004 in both regions (Fig. 6).

Table 2. Themisto libellula. Summary of 2-way ANCOVA on individual wet mass with Zone and Year as factors and Length as the covariate. $\mathrm{SS}=$ sum of squares, $\mathrm{df}=$ degrees of freedom, $\mathrm{MS}=$ mean square

\begin{tabular}{|lrrrrr|}
\hline Source of variation & SS & df & MS & F-ratio & p \\
\hline Zone & 0.002 & 1 & 0.002 & 0.389 & 0.53 \\
Year & 0.413 & 2 & 0.207 & 50.002 & $<0.01$ \\
Zone $\times$ Year & 0.010 & 2 & 0.005 & 1.257 & 0.28 \\
Length & 20.099 & 1 & 20.099 & 4864.238 & $<0.01$ \\
Error & 2.392 & 579 & 0.004 & & \\
\hline
\end{tabular}




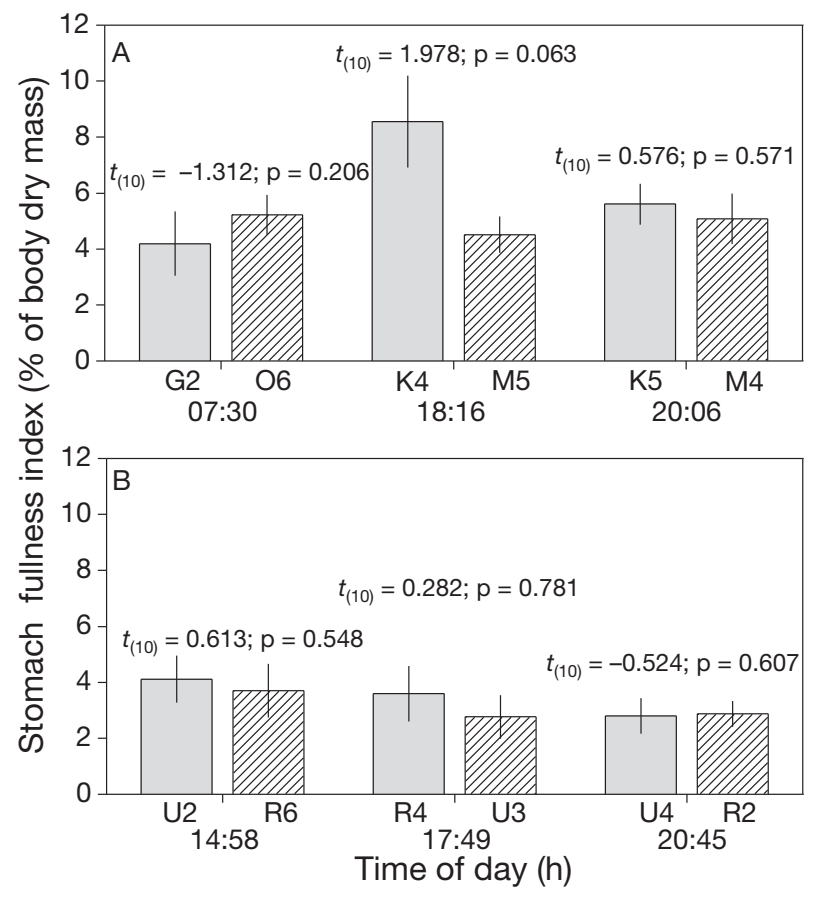

Fig. 4. Themisto libellula. Spatial variation in stomach fullness index (SFI) (mean \pm SE) in (A) the LSLE and (B) the NWGSL in fall 2004 at 2 stations sampled at the same time of the day. Results of the Student's $t$-test comparing the mean SFI $\left(\log _{10}\right)$ between 2 stations chosen at the same hour are also shown

The circadian cycles in SFI and DI were tested statistically with GAMs using all data combined (SFI for regions and years; DI for regions in 2003) (Fig. 7). There was a significant and a marginally significant effect of the time of day on both SFI $\left(F_{(5.65,51.35)}=2.27\right.$, $\mathrm{p}=0.031)$ and DI $\left(F_{(3.79,15.21)}=2.43, \mathrm{p}=0.065\right)$, respectively. These results confirmed that Themisto libellula was a nocturnal feeder and that a large part of the stomach contents was digested during the daylight period (Fig. 7). Nevertheless, SFI increased slightly during the afternoon and sunset periods. This suggests that T. libellula also acquired some food during the latter part of the daytime period (Fig. 7). Moreover, the curves of the SFI and DI versus time fitted by GAMs allowed the estimation of the digestion time (DT) of $T$. libellula as the difference between the time of the day when the highest values of both SFI and DI were observed. In the present study, the highest values of SFI and DI were observed at 05:00 and 18:00 h, respectively; thus, the DT was estimated to be ca. $13 \mathrm{~h}$ in both regions (Fig. 7).

\section{Stomach content analysis}

The average numbers and percentages of different prey items found in the stomach contents of Themisto libellula sampled ca. every $3 \mathrm{~h}$ over a $24 \mathrm{~h}$ period in each region (LSLE and NWGSL) in fall 2003 was determined (Table 3, Fig. 8). A total of 206 stomachs (110 ind. in the LSLE and 96 in the NWGSL) were examined, $18(8.7 \%)$ of which were empty (Table 3$)$.

The mean number of food items varied between 2.9 and 13.1 amphipod $^{-1}$ in both regions. This diet was mostly composed of copepods, which made up between 83 and $97 \%$ of the number of food items (Fig. 8A). Amphipods, chaetognaths, euphausiids, isopods and mysids accounted for the remainder of the prey. Euphausiids, mainly adults, were found to be the third most frequently identified prey within the stomach contents. The mean number of euphausiids eaten per amphipod at different times of the day varied between 0 and 0.5 ind. amphipod ${ }^{-1}$ in both regions, and they were found in the stomach contents of at least 1 Themisto libellula in almost all periods of the day in both regions (Table 3). Chaetognaths followed euphausiids, with an average of 0.2 ind. amphipod ${ }^{-1}$ $\mathrm{d}^{-1}$ for the 2 zones, but they were present in the stomach contents during only half of the periods of the day

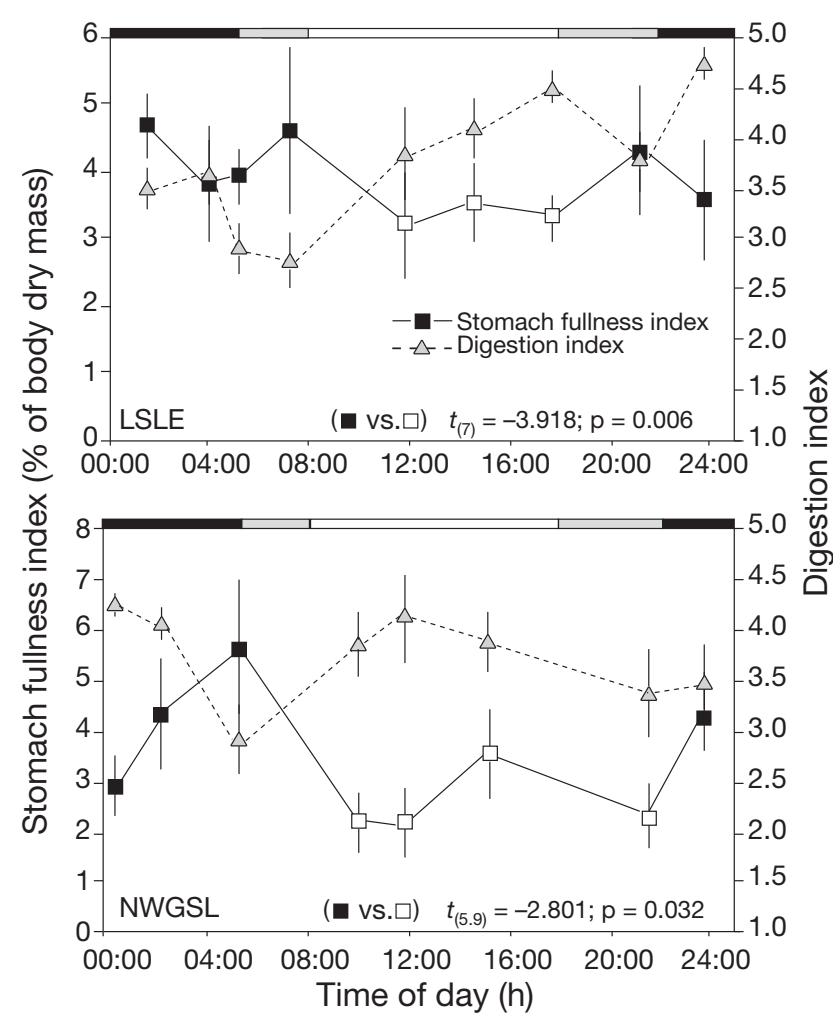

Fig. 5. Themisto libellula. Diel variation of the stomach fullness index (squares) and digestion index (triangles) (means \pm SE) in the LSLE and the NWGSL in fall 2003. The upper axis indicates daytime (in white), periods of sunset and sunrise (in grey), and nighttime (in black). Results of the Student's $t$-test on separate variance comparing mean SFI $\left(\log _{10}\right)$ during

(匹) night and ( $\square$ ) day are also shown 
LSLE
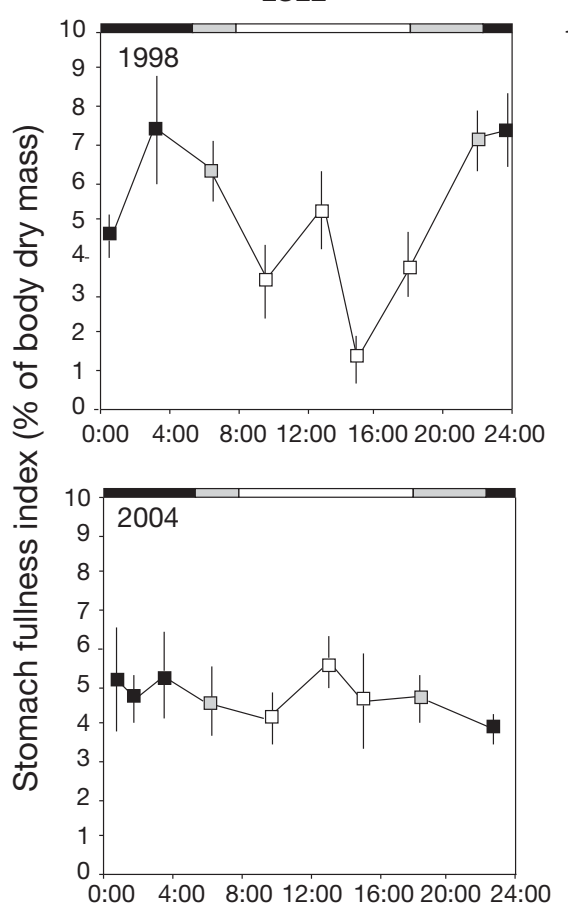

NWGSL
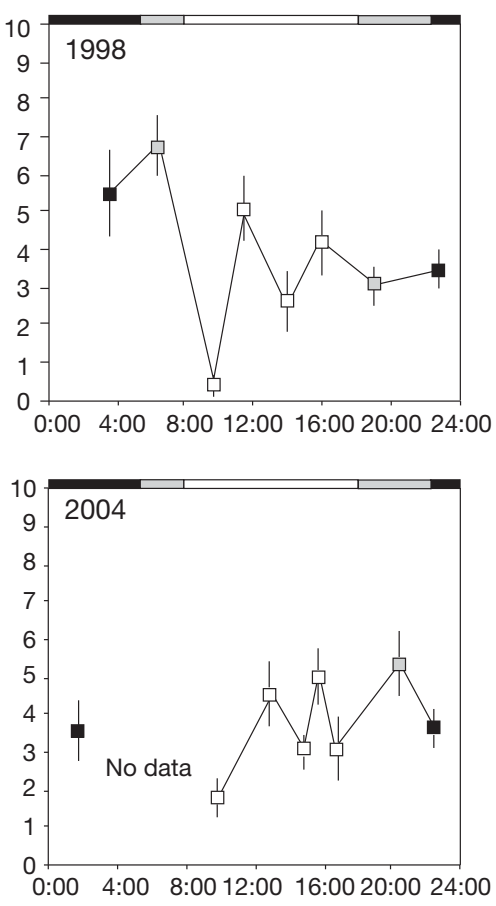

Time of day (h)

Fig. 6. Themisto libellula. Diel variation of the stomach fullness index (mean \pm SE) in the LSLE and the NWGSL in fall of 1998 and 2004. The upper axis indicates daytime (in white), periods of sunset and sunrise (in grey), and nighttime (in black)

analyzed in both regions. Isopods and mysids were only present in the NWGSL and only at 1 period of the day (Table 3 ). Thus, these 2 categories can be considered as occasional prey.

The mean number of copepods found in the stomach contents at different times of the day varied between 2.5 and 12.7 ind. amphipod ${ }^{-1}$ in both regions (Table 3). Calanus finmarchicus was the most abundant species, representing 45 to $75 \%$ and 10 to $75 \%$ of the total number of copepods found in the stomach contents of Themisto libellula in the LSLE and the NWGSL, respectively (Fig. 8B). This species was represented mostly by the copepodid and adult stages CIV, CV, CVI-females (F) and CVI-males (M) (Fig. 8C). Of these stages, CV was the most abundant food item, repre-

Fig. 7. Themisto libellula. General additive models (GAMs) showing the diel variation in stomach fullness index (SFI) for all regions and years, and digestion index (DI) for all regions in 2003. The thick lines show the fitted relationships based on GAMs; shaded bands are \pm 2 SE. The upper axis indicates daytime (in white), periods of sunset and sunrise (in grey), and nighttime (in black). The digestion time (DT) was estimated by calculating the difference between the time of the day when the highest values of the SFI and DI were observed. senting 70 and $63 \%$ of the C. finmarchicus found in stomach contents in the LSLE and the NWGSL, respetively. Moreover, C. finmarchicus stage $\mathrm{CV}$ also represented between 23 and $48 \%$ of the total number of food items found at different times of the day in both regions except during 1 of the 2 midnight periods sampled in each region (see Fig. 8C). Thus, C. finmarchicus stage $\mathrm{CV}$ was the most abundant food item found in this study. Three times as many specimens of CIV were found in amphipods from the NWGSL $(24.2 \%)$ than in the LSLE $(8.6 \%)$ for all sampled periods, and females were mostly found in the stomach contents during the dark period in both regions and males during the daylight period in the LSLE (Fig. 8C).

Calanus hyperboreus were present, but did not make up a major component of the amphipod diet (Table 3, Fig. 8B). Acartia longiremis, Euchaeta norvegica, Metridia longa, Microcalanus spp., Oithona spp. and Pseudocalanus spp. were the other copepods consumed by Themisto libellula in both regions (Table 3). Four copepod species, $M$. longa, E. norvegica, Pseudocalanus sp. and A. longiremis were found in the stomach contents of T. libellula during almost all periods of the day in the LSLE. Among these species, the most abundant was M. longa, with an average abundance of 0.52 ind. amphipod ${ }^{-1}$, fol-

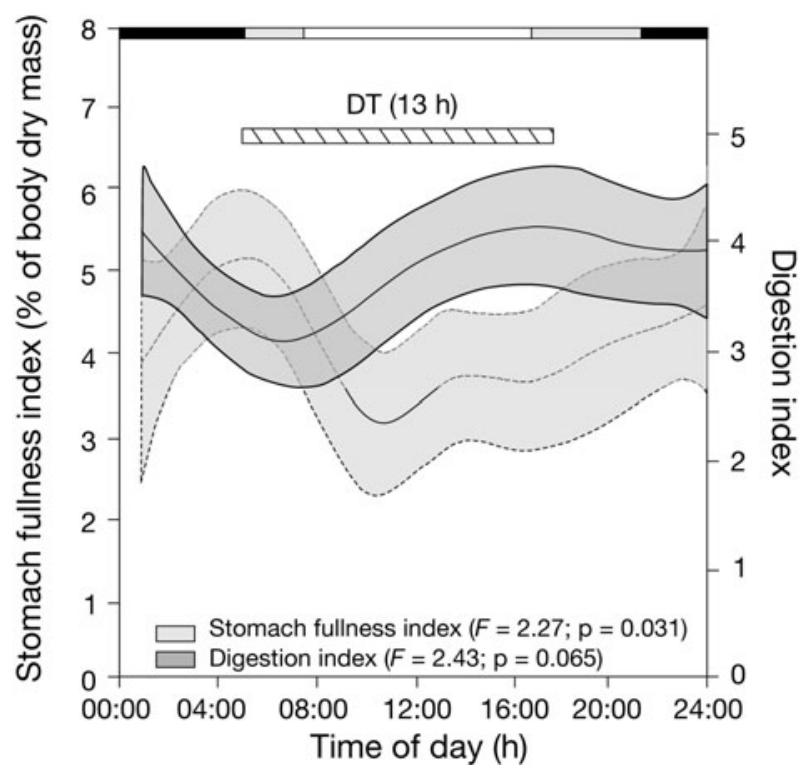


Table 3. Themisto libellula. Diet composition and mean number of prey items per amphipod sampled at zones LSLE and NWGSL and sampling time of day (h) in fall 2003. (-) Not found

\begin{tabular}{|c|c|c|c|c|c|c|c|c|c|c|c|c|c|c|c|c|c|}
\hline \multirow[t]{2}{*}{ Prey identification } & \multicolumn{9}{|c|}{ - LSLE - } & \multicolumn{8}{|c|}{ NWGSL } \\
\hline & 01:29 & $03: 52$ & $05: 12$ & $07: 14$ & $11: 40$ & $14: 36$ & $17: 44$ & $21: 47$ & $23: 47$ & $00: 18$ & 02:09 & $05: 12$ & $09: 55$ & $11: 45$ & $15: 00$ & $21: 30$ & $23: 46$ \\
\hline \multicolumn{18}{|l|}{ Amphipods } \\
\hline Unidentified amphipods & - & 0.2 & 0.1 & - & - & - & 0.1 & - & - & - & - & - & 0.1 & - & 0.1 & - & - \\
\hline \multicolumn{18}{|l|}{ Chaetognaths } \\
\hline Unidentified chaetognaths & 0.1 & - & 0.3 & 0.1 & - & 0.3 & - & - & - & 0.1 & - & 0.1 & - & 0.4 & 0.1 & - & 0.1 \\
\hline \multicolumn{18}{|l|}{ Calanus copepods } \\
\hline Unidentified Calanus & 0.7 & 1.0 & 0.6 & 1.2 & 0.2 & 0.9 & - & 0.5 & 0.1 & 2.2 & 0.7 & 2.0 & 0.5 & 1.3 & 0.4 & 0.2 & 0.6 \\
\hline C. finmarchicus & 5.9 & 3.4 & 7.9 & 7.9 & 1.3 & 3.3 & 3.6 & 3.5 & 1.6 & 0.4 & 2.8 & 6.4 & 1.2 & 1.5 & 2.6 & 1.9 & 6.3 \\
\hline C. hyperboreus & - & 0.1 & 0.3 & 0.5 & - & - & - & - & - & - & 0.1 & 0.7 & - & 0.1 & 0.1 & 0.1 & - \\
\hline \multicolumn{18}{|l|}{ Other copepods } \\
\hline Acartia longiremis & - & 0.1 & 0.1 & 0.3 & 0.3 & - & 0.1 & 0.1 & 0.2 & - & - & - & - & - & - & 0.3 & 0.1 \\
\hline Euchaeta norvegica & 0.4 & 0.3 & 0.6 & 0.6 & 0.2 & 0.6 & - & 0.5 & 0.1 & - & 0.1 & 0.3 & 0.3 & 0.2 & - & 0.2 & 0.3 \\
\hline Metridia longa & 0.9 & 0.7 & 0.3 & 0.4 & 0.2 & 0.8 & 0.8 & 0.5 & 0.1 & - & - & 0.2 & - & - & - & 0.5 & 0.2 \\
\hline Microcalanus spp. & 0.2 & 0.1 & 0.2 & 0.3 & 0.1 & - & - & - & - & - & - & - & - & - & - & - & 0.4 \\
\hline Oithona spp. & - & - & 0.1 & 0.8 & - & - & - & 0.2 & 0.1 & - & - & 0.1 & - & - & - & 0.1 & - \\
\hline Pseudocalanus spp. & 0.1 & - & 0.2 & 0.5 & - & 0.5 & 0.1 & - & - & - & 0.1 & 0.5 & 0.1 & 0.1 & - & - & 0.3 \\
\hline Unidentified copepods & 0.7 & 0.6 & 0.5 & 0.2 & 0.2 & 1.1 & 0.8 & 0.8 & 0.3 & 0.1 & 0.4 & 1.2 & 1.1 & 0.6 & 0.2 & 0.2 & 1.1 \\
\hline \multicolumn{18}{|l|}{ Euphausiids } \\
\hline $\begin{array}{l}\text { Unidentified adults } \\
\text { euphausiids }\end{array}$ & 0.4 & 0.6 & 0.3 & 0.1 & 0.4 & - & 0.5 & - & 0.4 & 0.1 & 0.5 & 0.3 & 0.1 & - & 0.2 & 0.7 & 0.4 \\
\hline \multicolumn{18}{|l|}{ Isopods } \\
\hline Unidentified isopods & - & - & - & - & - & - & - & - & - & - & - & 0.1 & - & - & - & - & - \\
\hline \multicolumn{18}{|l|}{ Mysids } \\
\hline Unidentified adults mysids & s- & - & - & - & - & - & - & - & - & - & 0.1 & - & - & - & - & - & - \\
\hline \multicolumn{18}{|l|}{ Other items and debris } \\
\hline Unidentified & 0.1 & - & 0.1 & 0.2 & - & - & - & 0.5 & 0.1 & 0.1 & 0.2 & - & - & - & 0.3 & - & - \\
\hline No. of stomachs examined & 20 & 10 & 20 & 10 & 10 & 10 & 10 & 10 & 10 & 16 & 20 & 10 & 10 & 10 & 10 & 10 & 10 \\
\hline No. of empty stomachs & 0 & 1 & 1 & 1 & 2 & 1 & 0 & 1 & 2 & 4 & 1 & 0 & 3 & 0 & 0 & 1 & 0 \\
\hline $\begin{array}{l}\text { Mean number of prey } \\
\text { per amphipod }\end{array}$ & 9.3 & 7.1 & 11.2 & 13.1 & 2.9 & 7.5 & 6.0 & 6.6 & 3.0 & 3.1 & 4.8 & 11.9 & 3.4 & 4.2 & 4.0 & 4.2 & 9.8 \\
\hline $\begin{array}{l}\text { Mean biomass of prey per } \\
\text { amphipod (mg) }\end{array}$ & 6.0 & 7.0 & 6.9 & 7.1 & 3.2 & 4.1 & 4.6 & 3.8 & 3.2 & 3.2 & 5.2 & 7.2 & 2.9 & 2.5 & 3.1 & 5.0 & 5.7 \\
\hline
\end{tabular}

lowed by E. norvegica (0.37 ind. amphipod $\left.{ }^{-1}\right)$, Pseudocalanus spp. (0.16 ind. amphipod ${ }^{-1}$ ), and A. longiremis (0.13 ind. amphipod $\left.{ }^{-1}\right)$. On the other hand, only 2 copepod species, E. norvegica and Pseudocalanus sp., were present in amphipod stomachs during almost all periods of the day in the NWGSL, with an average abundance of 0.18 and 0.14 ind. amphipod ${ }^{-1}$, respectively. Finally, 2 very small genera of copepods, Oithona (spp.) and Microcalanus (spp.), were found in the stomach contents of $T$. libellula at different periods of the day, principally in the LSLE (Table 3, Fig. 8B).

The average contribution, in percentage, of prey items to the biomass (mg) of Themisto libellula stomach contents sampled in fall 2003 in both regions was estimated (Fig. 9). Even though there are differences in caloric densities of different prey species, energy intake is strongly correlated to prey biomass. The mean biomass of food items varied between 4.1 and $29.2 \mathrm{mg} \mathrm{amphipod}^{-1}$. This diet was mostly composed of copepods and euphausiids, which made up between 28 and $96 \%$ and between 0 and $71 \%$ of prey biomass, respectively, depending on time of day (Fig. 9).
Amphipods, chaetognaths, isopods and mysids accounted for the remainder of the prey and they contributed between 0 and $26 \%$ of the food item biomass.

\section{Daily ingestion rate}

Two approaches were used to estimate the DIR of Themisto libellula in both regions (LSLE and NWGSL) in fall 1998 (Approach 1), 2003 (Approaches 1 and 2), and 2004 (Approach 1) (Tables 4 \& 5). According to the approach based on SFI $\left(\mathrm{DIR}_{1}\right)$, the $24 \mathrm{~h}$ integrated SFI $(G)$ expressed in percentage of amphipod body dry mass, varied between 3.42 and $5.16 \%$ in both regions in fall 1998, 2003 and 2004 (Table 4). Using the estimated digestion time of $13 \mathrm{~h}$ obtained from the GAMs (Fig. 7), DIR 1 varied between 7.19 and $9.54 \%$ of the amphipod body dry mass per day in the LSLE and between 6.32 and $7.19 \%$ in the NWGSL during the $3 \mathrm{yr}$ (Table 4). In the second approach, based on the calculation of the mean biomass of prey removed per unit of time, $\mathrm{DIR}_{2}$ was estimated to be 16.39 and $16.82 \%$ of the 

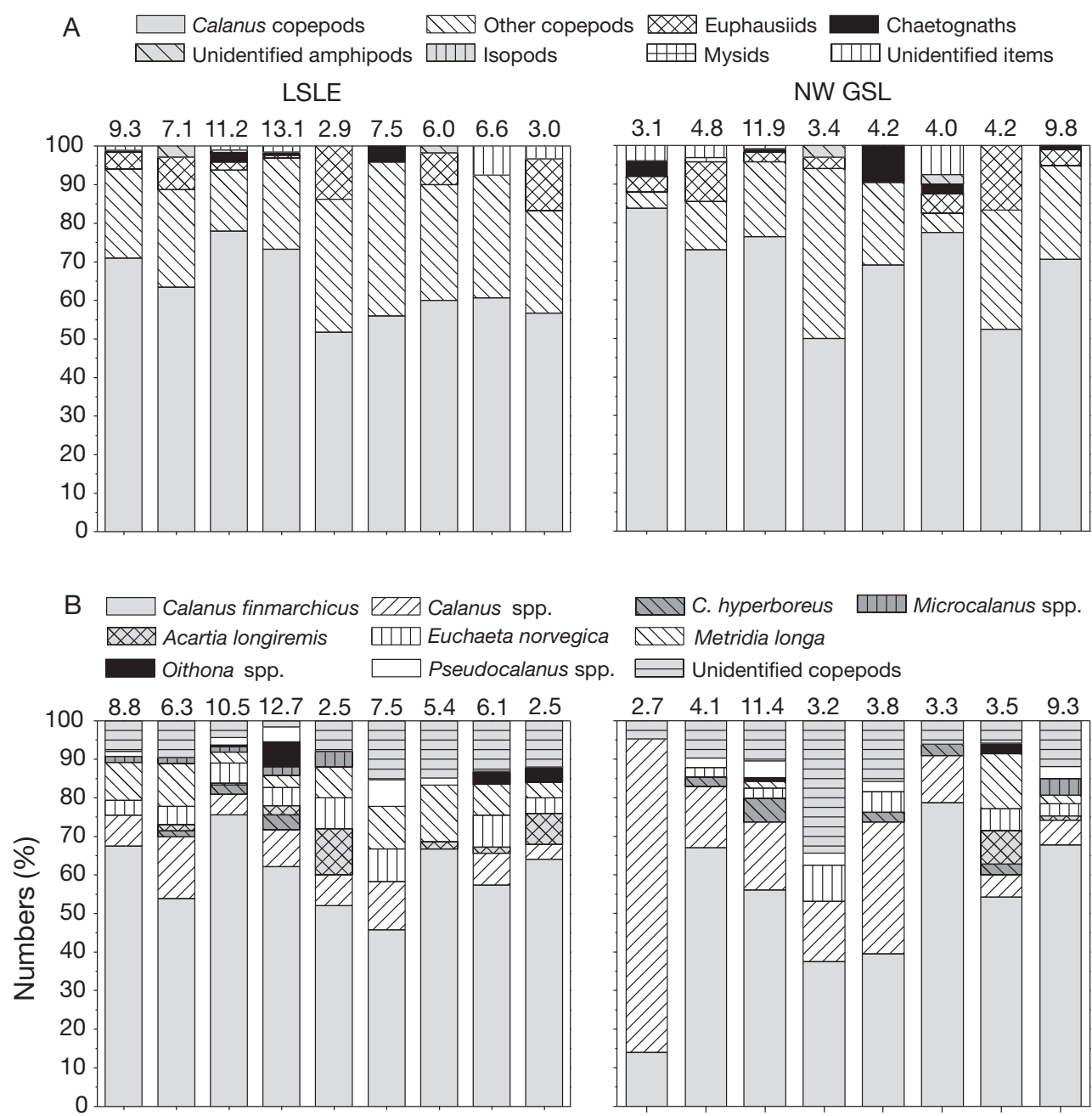

MIV C. hyperboreus $\square \amalg$ Microcalanus spp.

\section{Metridia longa}

$\rightleftarrows$ Unidentified copepods
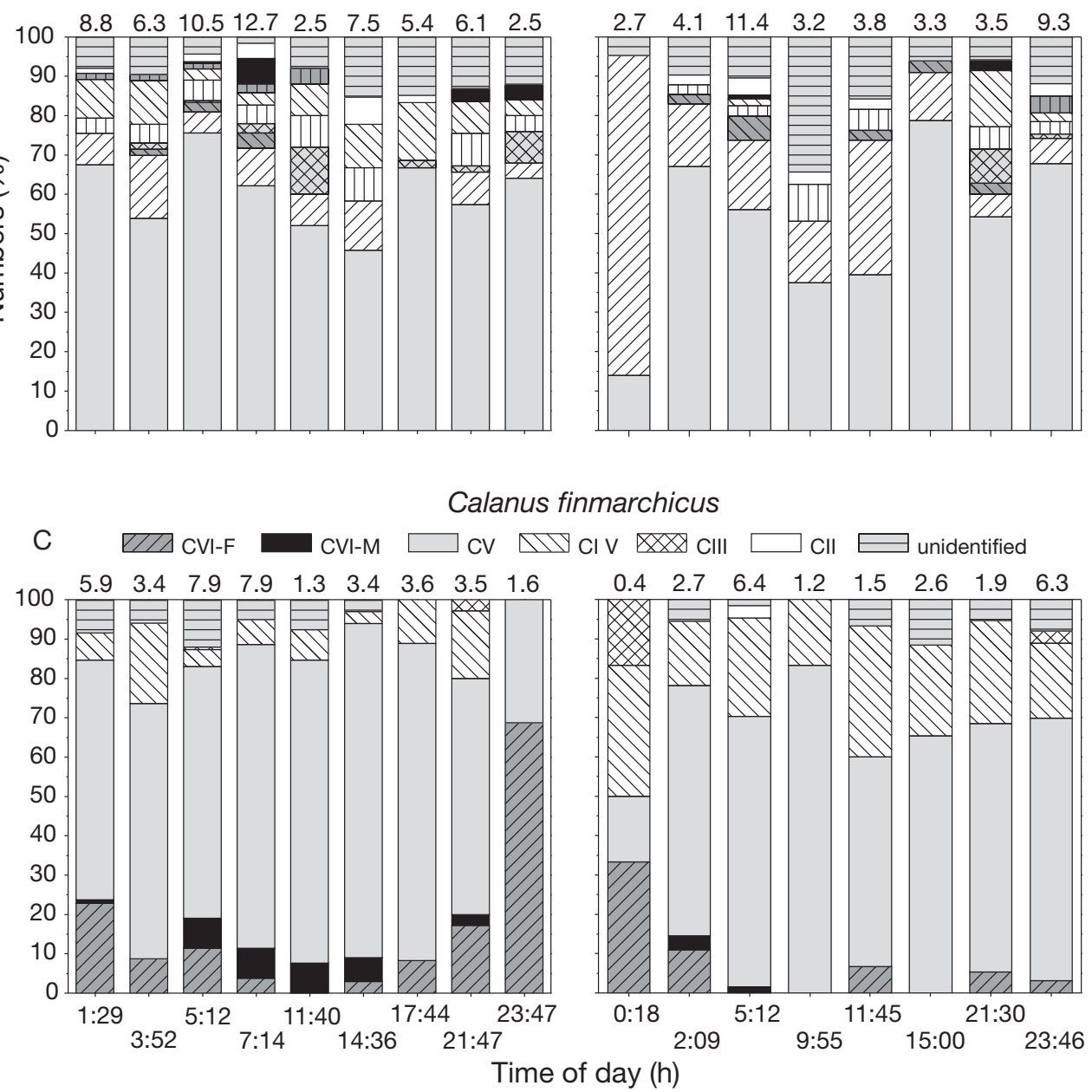

Fig. 8. Themisto libellula. Diel variation in the prey composition in the LSLE and NWGSL in fall 2003. (A) General prey items; (B) Calanus and other copepods; (C) Calanus finmarchicus copepodids and adult developmental stages. F: females, M: males. Numbers above the bars = mean number of prey eaten per amphipod 


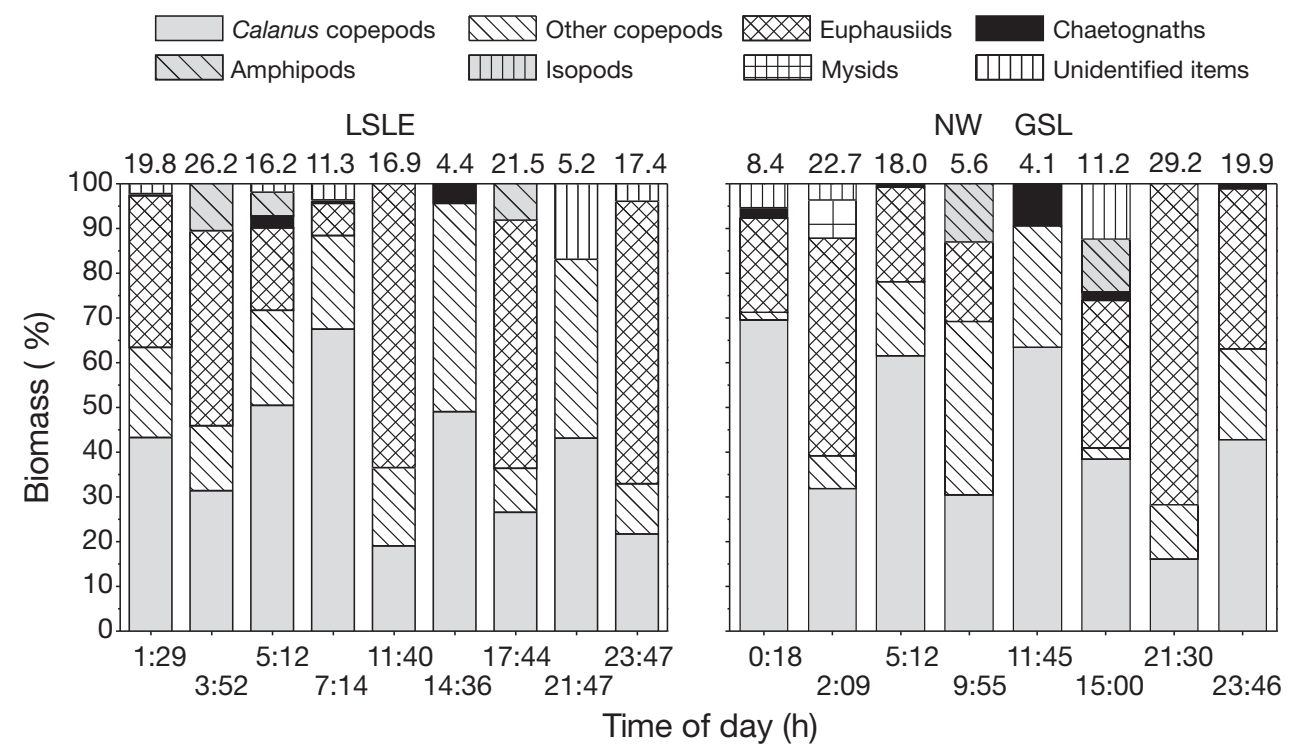

Fig. 9. Themisto libellula. Diel variation in the prey biomass in the LSLE and NWGSL in fall 2003. Numbers above the bars $=$ mean biomass of prey eaten per amphipod

amphipod body dry mass per day in the LSLE and the NWGSL, respectively, in fall 2003 (Table 5). If we consider only Calanus finmarchicus, $\mathrm{DIR}_{i}$ was estimated at 4.02 and $3.40 \%$ of the amphipod body dry mass per day in the LSLE and the NWGSL, respectively (Table 5).

\section{Predation impact}

The daily predation impact on the overall meso- and macrozooplankton community was estimated in each region (LSLE and NWGSL) for 3 yr using DIR $_{1}$ (Table 4). Overall predation impact was also studied by the second approach, based on feeding rates for each prey category, in both regions, but for 2003 only (Table 5). This approach made it possible to assess predation impact on species of prey and even on specific

Table 4. Themisto libellula. Estimates of the daily ingestion rate $\left(\mathrm{DIR}_{1}\right)$ based on stomach fullness index (SFI) in individuals sampled in the LSLE and NWGSL in the fall of 1998, 2003 and 2004. DM = dry mass

\begin{tabular}{|lccc|}
\hline Sampling zone & Year & $\begin{array}{c}\text { SFI } \\
\text { (\% body DM) }\end{array}$ & $\begin{array}{c}\text { DIR }_{1} \\
\text { (\% body DM d }\end{array}$ \\
\hline LSLE & 1998 & 5.16 & 9.54 \\
& 2003 & 3.89 & 7.19 \\
NWGSL & 2004 & 4.73 & 8.74 \\
& 1998 & 3.89 & 7.19 \\
& 2003 & 3.42 & 6.32 \\
& 2004 & 3.75 & 6.92 \\
\hline
\end{tabular}

Table 5. Themisto libellula. Estimates of daily ingestion rates $\left(\mathrm{DIR}_{2}\right)$ in mesozooplankton and macrozooplankton and Calanus finmarchicus sampled in the LSLE and NWGSL in fall 2003. These DIR were based on number of prey items found in amphipod stomachs and their estimated dry mass

$(\mathrm{DM}) . \mathrm{FR}=$ feeding rates, $\mathrm{BP}=$ average biomass of prey

\begin{tabular}{|lcccc|}
\hline Organism & $\begin{array}{c}\text { Sampling } \\
\text { zone }\end{array}$ & $\begin{array}{c}\text { Mean } \\
(\mathrm{mg})\end{array}$ & $\begin{array}{c}\mathrm{FR} \\
\left(\mathrm{mg} \mathrm{d}^{-1}\right)\end{array}$ & $\begin{array}{c}\mathrm{DIR}_{2} \\
(\% \text { body } \\
\left.\mathrm{DM} \mathrm{d}^{-1}\right)\end{array}$ \\
\hline $\begin{array}{lcccc}\text { Mesozooplankton and } \\
\text { macrozooplankton }\end{array}$ & LWLE & 5.10 & 8.88 & 16.39 \\
C. finmarchicus & LSLE & 4.40 & 9.11 & 16.82 \\
& NWGSL & 0.84 & 1.84 & 4.02 \\
& & & & \\
\hline
\end{tabular}

copepod stages. The calculated daily predation impact using the SFI approach (Approach 1) was generally low, accounting for $<0.8 \%$ of the zooplankton standing stock in both regions in the fall of 1998, 2003 and 2004 (Table 6). The average value of the daily predation impact estimated in 1998, 2003 and 2004 was 3.6 times higher in the LSLE than in the NWGSL (Approach 1). On the other hand, the calculated daily predation impact using the feeding rate approach (Approach 2) was 3 times higher than in the first approach, accounting for 1.79 and $0.49 \%$ of the zooplankton standing stock in the LSLE and the NWGSL, respectively (Table 6).

The daily predation impact on the standing stocks of various copepod species found in the stomach contents of Themisto libellula in both regions in fall 2003, including the different copepodid stages of Calanus 
Table 6. Themisto libellula. Predation impact on mesozooplankton and macrozooplankton standing stock in fall 1998,2003 and 2004 in the St. Lawrence marine system. Predation on the overall meso- and macrozooplankton community was estimated using both $\mathrm{DIR}_{1}$ (based on the stomach fullness index) and $\mathrm{DIR}_{2}$ (where the mean number of prey is converted to prey biomass). Predation on Calanus finmarchicus was estimated using the sum of $\mathrm{DIR}_{i}$ for different stages of this species. Zooplankton biomass data came from the Atlantic Zone Monitoring Program in 2003 (Harvey et al. 2008). DM = dry mass

\begin{tabular}{|c|c|c|c|c|c|c|c|}
\hline $\begin{array}{l}\text { Estimation of dail } \\
\text { ingestion rate }\end{array}$ & Organism & $\begin{array}{l}\text { Sampling } \\
\text { zone }\end{array}$ & Year & $\begin{array}{c}\text { Zooplankton } \\
\text { biomass } \\
\left(\mathrm{g} \mathrm{DM} \mathrm{m}^{-2}\right)\end{array}$ & \multicolumn{2}{|c|}{ Themisto libellula } & $\begin{array}{c}\text { Daily predation } \\
\text { impact } \\
\text { (\% biomass) }\end{array}$ \\
\hline \multirow[t]{6}{*}{$\mathrm{DIR}_{1}$} & \multirow{6}{*}{$\begin{array}{l}\text { Mesozooplankton and } \\
\text { macrozooplankton }\end{array}$} & LSLE & 1998 & 19.31 & 11.67 & 0.46 & 0.23 \\
\hline & & & 2003 & 11.47 & 23.26 & 1.25 & 0.77 \\
\hline & & & 2004 & 17.80 & 27.85 & 1.55 & 0.76 \\
\hline & & NWGSL & 1998 & 20.49 & 10.64 & 0.41 & 0.14 \\
\hline & & & 2003 & 20.05 & 13.65 & 0.58 & 0.18 \\
\hline & & & 2004 & 23.58 & 11.86 & 0.59 & 0.17 \\
\hline \multirow[t]{4}{*}{$\mathrm{DIR}_{2}$} & \multirow{2}{*}{$\begin{array}{l}\text { Mesozooplankton and } \\
\text { macrozooplankton }\end{array}$} & LSLE & 2003 & 11.47 & 23.26 & 1.25 & 1.79 \\
\hline & & NWGSL & & 20.05 & 13.65 & 0.58 & 0.49 \\
\hline & \multirow[t]{2}{*}{ C. finmarchicus } & LSLE & 2003 & 2.03 & 23.26 & 1.25 & 2.48 \\
\hline & & NWGSL & & 4.61 & 13.65 & 0.58 & 0.43 \\
\hline
\end{tabular}

Table 7. Themisto libellula. Predation impact on copepod population standing stocks in the St. Lawrence marine system in fall 2003. Copepod biomass was estimated from data of the Atlantic Zone Monitoring Program collected in 2003 (Harvey et al. 2008). Mean BPA is the average biomass of the prey ingested per amphipod during a $24 \mathrm{~h}$ period in fall 2003, FR = feeding rate calculated with the mean BPA, DIR = daily ingestion rate, DM = dry mass

\begin{tabular}{|c|c|c|c|c|c|c|}
\hline $\begin{array}{l}\text { Sampling } \\
\text { zone }\end{array}$ & Species & $\begin{array}{l}\text { Average biomass } \\
\quad\left(\mathrm{mg} \mathrm{m}^{-2}\right)\end{array}$ & $\begin{array}{l}\text { Mean } \mathrm{BP}_{i} \\
\quad(\mathrm{mg})\end{array}$ & $\begin{array}{c}\mathrm{FR}_{j} \\
\left(\mathrm{mg} \mathrm{d}^{-1}\right)\end{array}$ & $\begin{array}{c}\mathrm{DIR}_{2} \\
\left(\% \text { body } \mathrm{DM} \mathrm{d}^{-1}\right)\end{array}$ & $\begin{array}{l}\text { Daily predation } \\
\text { impact (\% biomass) }\end{array}$ \\
\hline \multirow[t]{15}{*}{ LSLE } & Calanus copepods & & & & & \\
\hline & C. finmarchicus & & & & & \\
\hline & CVI-females & 55.67 & 0.21 & 0.38 & 0.70 & 15.72 \\
\hline & CVI-males & 21.46 & 0.05 & 0.04 & 0.08 & 4.66 \\
\hline & $\mathrm{CV}$ & 1861.58 & 1.06 & 1.60 & 2.97 & 1.99 \\
\hline & CIV & 73.74 & 0.04 & 0.07 & 0.14 & 2.37 \\
\hline & CIII & 9.30 & $<0.01$ & $<0.01$ & $<0.01$ & $<0.01$ \\
\hline & C. hyperboreus & 6396.18 & 0.18 & 0.18 & 0.34 & 0.07 \\
\hline & Other copepods & & & & & \\
\hline & Acartia longiremis & 2.10 & 0.00 & 0.00 & 0.00 & 1.18 \\
\hline & Euchaeta norvegica & 97.85 & 0.79 & 1.35 & 2.49 & 31.81 \\
\hline & Metridia longa & 162.79 & 0.08 & 0.12 & 0.22 & 1.69 \\
\hline & Microcalanus spp. & 5.30 & $<0.01$ & $<0.01$ & $<0.01$ & 0.38 \\
\hline & Oithona spp. & 19.11 & $<0.01$ & $<0.01$ & $<0.01$ & 0.03 \\
\hline & Pseudocalanus spp. & 8.41 & $<0.01$ & $<0.01$ & $<0.01$ & 0.55 \\
\hline \multirow[t]{16}{*}{ NWGSL } & Calanus copepods & & & & & \\
\hline & C. finmarchicus & & & & & \\
\hline & CVI-females & 134.11 & 0.04 & 0.09 & 0.17 & 0.74 \\
\hline & CVI-males & 17.31 & 0.01 & 0.01 & 0.02 & 0.67 \\
\hline & $\mathrm{CV}$ & 3873.09 & 0.69 & 1.52 & 2.81 & 0.42 \\
\hline & CIV & 526.92 & 0.07 & 0.16 & 0.29 & 0.32 \\
\hline & CIII & 48.58 & $<0.01$ & $<0.01$ & $<0.01$ & 0.02 \\
\hline & CII & 3.82 & $<0.01$ & $<0.01$ & $<0.01$ & 0.09 \\
\hline & C. hyperboreus & 12315.61 & 0.13 & 0.24 & 0.44 & 0.02 \\
\hline & Other copepods & & & & & \\
\hline & Acartia longiremis & 1.40 & $<0.01$ & $<0.01$ & $<0.01$ & 0.41 \\
\hline & Euchaeta norvegica & 369.16 & 0.39 & 0.85 & 1.57 & 2.47 \\
\hline & Metridia longa & 260.08 & 0.02 & 0.03 & 0.06 & 0.13 \\
\hline & Microcalanus spp. & 3.66 & $<0.01$ & $<0.01$ & $<0.01$ & 0.18 \\
\hline & Oithona spp. & 21.89 & $<0.01$ & $<0.01$ & $<0.01$ & $<0.01$ \\
\hline & Pseudocalanus spp. & 28.73 & $<0.01$ & $<0.01$ & $<0.01$ & 0.08 \\
\hline
\end{tabular}


finmarchicus, was estimated using the second approach and varied from $<0.01$ to $31.81 \%$ and from $<0.01$ to $2.47 \%$ in the LSLE and the NWGSL, respectively (Table 7). The standing stocks that were most affected by the daily predation impact of $T$. libellula in the LSLE were Euchaeta norvegica $(31.8 \%), C$. finmarchicus (CVI-F, 15.7\%; CVI-M, 4.7\%; CV, $2.0 \%$; and CIV, $2.4 \%)$, Metridia longa (1.7\%) and Acartia longiremis $(1.2 \%)$. The standing stocks of these same species were also observed to be the most affected in the NWGSL, except for $M$. longa and A. longiremis. However, the daily predation impact on the standing stocks of each copepod species was about one order of magnitude higher in the LSLE than in the NWGSL (Table 7).

\section{DISCUSSION}

\section{Population structure}

The length-frequency distribution of Themisto libellula sampled in the LSLE and the NWGSL in September 1998 and 2003 and November 2004 revealed 2 size class intervals with median lengths of 30 and $42 \mathrm{~mm}$ in 1998, 33 and $42 \mathrm{~mm}$ in 2003, and 36 and $45 \mathrm{~mm}$ in 2004 in both regions. Observations made by Percy \& Fife (1993) in the Hudson Strait, and by different authors in other Arctic seas (see review in Auel \& Werner 2003) found that a cohort of juveniles measuring between 5 and $12 \mathrm{~mm}$ was usually present in August through September. However, this category of small individuals has never been observed during the annual macrozooplankton biomass monitoring survey, which has been carried out in early September in the LSLE and the NWGSL since 1994. In fact, May through June is the only period of the year when some small individuals (8 to $20 \mathrm{~mm}$ ) have been reported in the SLMS (Harvey et al. 2008).

The larger size class of Themisto libellula sampled in September in the GSL (median length $43 \mathrm{~mm}$ ) has been absent or poorly represented in net samples taken in August through September in the Hudson Strait, Hudson Bay, the Greenland, Norwegian and Barents seas, and central Fram Strait (Percy \& Fife 1993, Koszteyn et al. 1995, Dalpadado 2002, Auel \& Werner 2003). Based on the information provided by Auel \& Werner (2003), our study would be the first netbased study to report the presence of specimens of $T$. libellula larger than $40 \mathrm{~mm}$. This group represented between 4 and $40 \%$ of the total number of individuals sampled in each region in the fall of 1998, 2003 and 2004. Before our study, such large T. libellula individuals (between 43 and $50 \mathrm{~mm}$ ) had been observed only in ringed seal Pusa hispida and cod Gadus morhua stom- achs (T. libellula 47 and $50 \mathrm{~mm}$ ) at Baffin Island and the Barents Sea (Dunbar 1957, Dalpadado et al. 2001). Both predators appear to select for the larger individuals of the Themisto population (Dunbar 1957, Dalpadado et al. 2001).

The difference in the median size of the larger Themisto libellula sampled in the SLMS and in some Arctic seas cannot be attributed to net avoidance since they were sampled with the same type of plankton net in both areas $\left(1 \mathrm{~m}^{2}\right.$ BIONESS, $1 \mathrm{~m}^{2}$ MOCNESS, $8 \mathrm{~m}^{2}$ rectangular midwater trawl). Also, this difference cannot be attributed to the seawater temperature during the summer season since T. libellula lives permanently in the cold intermediate layer (CIL) in the SLMS at temperatures varying between -1 and $+3^{\circ} \mathrm{C}$ (Harvey et al. 2008). This is comparable with the temperatures of the surface layer during the summer season in various Arctic seas where $T$. libellula has been observed (see Auel \& Werner 2003). The quantity and the nutritive value of the food items as well as the length of the rich nutritive season (April to November) in the GSL region may account for the difference in the median size of $T$. libellula observed between the SLMS and Arctic seas. It is not clear why cod were able to find large individuals of T. libellula in the same regions and in the same years as net samples obtained by Dalpadado et al. (2001), but it suggests that there is a more pronounced spatial segregation between the 2 size classes in the Barents Sea than in the SLMS.

\section{Feeding ecology}

This study is the first to examine and statistically test the diel feeding pattern of a macrozooplankton organism using GAMs. Based on the model results, Themisto libellula consumed prey mostly during the latter part of the night and the sunrise period, while much of the stomach contents were digested during the daylight period. The graphical examination of the daily pattern of variation of the SFI over a $24 \mathrm{~h}$ period, along with GAMs, suggested that T. libellula also acquired a small quantity of food during the afternoon and before the sunset period. The enhanced feeding of $T$. libellula during the sunrise and before the sunset periods is consistent with results obtained by Fortier et al. (2001). In that study, which was conducted at Barrow Strait and at the ice-water interface during the midnight sun period, the SFI of $T$. libellula was greatest in late evening when light intensity was near minimum, and in late morning when light was near maximum. In South Georgia (southern Atlantic Ocean) and in the Prince Edward Archipelago (southern Indian Ocean), T. gaudichaudi also has a diurnal feeding activity with 2 distinct peaks occurring just after sunrise and before 
sunset (Kane 1963, Pakhomov \& Perissinotto 1996, Froneman et al. 2000). Another species, T. japonica, also has a diel feeding activity pattern with 2 distinct peaks except that it feeds more actively during the day than during the night-about half that of daytime (Yamashita et al. 1984).

The results of the stomach content analyses suggest a close relationship between the structure of the local zooplankton community and the diet composition of Themisto libellula. Stomach contents indicated that T. libellula occupies an important trophic status as zooplankton consumers in the SLMS. In numbers and in mass, zooplankton organisms, such as copepods, euphausiids and chaetognaths, constituted the bulk of its diet during the fall season. Amphipods of the genus Themisto are known to be mainly carnivorous predators, principally of zooplankton (Kane 1963, Sheader \& Evans 1975). The diverse dietary composition of $T$. libellula in the present study was in agreement with studies on $T$. gaudichaudi, which was recognized as a visual opportunistic predator, also consuming copepods, euphausiids, pteropods and chaetognaths (Pakhomov \& Perissinotto 1996). Our study emphasized the dominance of copepods in the diet of T. libellula in the fall, and especially of Calanus copepods. This pattern has also been observed in other regions (Dunbar 1946, Falk-Petersen et al. 1987, Fortier et al. 2001, Auel et al. 2002). In terms of mass, both copepods and euphausiids represent the main sources of energy of T. libellula in the SLMS during the fall season.

There was a close relationship between the vertical distribution of the local zooplankton community and the diet composition of Themisto libellula. Its feeding pattern reflected the well-known diel migration patterns of mesozooplankton and of T. libellula itself. In the SLMS, T. libellula remains permanently within the CIL (isotherm $<3^{\circ} \mathrm{C}$ ), migrating to its lower $(\sim 150 \mathrm{~m})$ and upper ( 25 $\mathrm{m}$ ) limits during the day and the night, respectively (Harvey et al. 2008). During the fall, more than $50 \%$ of Calanus finmarchicus CIV and CV, the numerically dominant prey items found in the stomach contents of T. libellula, and $75 \%$ of the C. finmarchicus females are also present in the CIL (between 25 and $150 \mathrm{~m}$ ) during the day. However, C. finmarchicus migrates to the surface layer (between 0 and $\sim 25 \mathrm{~m}$ ) during the night (Zakardjian et al. 1999). The migration of $C$. finmarchicus between the CIL and the surface layer probably occurs around sunrise (descending) and sunset (ascending) periods, which coincides with the fact that in the present study $T$. libellula consumed C. finmarchicus CIV and CV in large and small quantities around sunrise and sunset periods, respectively. Among the other copepod species frequently observed in the stomach contents of $T$. libellula from both regions, Metridia longa, Microcalanus spp. and
Euchaeta norvegica were likewise present in the CIL (between 25 and $150 \mathrm{~m}$ ) during the day and migrated to the surface layer (between 0 and $\sim 25 \mathrm{~m}$ ) during the night (Plourde et al. 2002).

Compared with the other copepod species, Calanus hyperboreus, Pseudocalanus spp., Acartia longiremis and Oithona spp. were observed in relatively low frequencies in the stomach contents of Themisto libellula. This could be explained by the fact that during the fall the greater portion of these copepod populations were either in diapause in the deep layer between 200 and $300 \mathrm{~m}$ (C. hyperboreus) or residing in the surface layer during the daytime and the nighttime (Pseudocalanus spp., Acartia longiremis and Oithona spp.) (Plourde et al. 2002). Only a small percentage of these populations $(<10 \%)$ are present in the CIL (isotherm $<3^{\circ} \mathrm{C}$ ) at this time of the year.

Two of the more important macrozooplankton groups found in the stomach contents of Themisto libellula in both regions were the euphausiids and chaetognaths. These groups also reside in the CIL during the day and migrate to the surface layer during the night (Sameoto \& Jaroszynski 1973, Harvey et al. 2008). In contrast, another group, the mysids, occupy the deep layer night and day, displaying little vertical displacement except in the NWGSL region, where a small proportion of the population move up slightly to the lower part of the CIL during the nighttime (Harvey et al. 2008).

In conclusion, the high degree of overlap in the vertical distributions of prey such as Calanus finmarchicus (CIV and CV and females), Metridia longa, Microcalanus spp. and euphausiids during both day and night, were reflected by their high presence in the stomach contents of Themisto libellula in the SLMS. In particular, the high abundance of the CV stage in autumn, which is characteristic of $C$. finmarchicus (Plourde et al. 2001), accounted for their dominance as prey of T. libellula. Thus, T. libellula was able to efficiently exploit the diel-migratory zooplankton community in these regions. The results of our stomach content analyses lead to the conclusion that $T$. libellula is an opportunistic predator that can feed on a variety of prey of appropriate size present in its habitat (CIL) during the day and night periods. Furthermore, feeding activity and daily ingestion rates will be greatly influenced by the degree of overlap between the vertical distributions of $T$. libellula and its prey.

\section{Daily ration}

The DT of Themisto libellula obtained in the present study $(13 \mathrm{~h})$ is ca. 1.7 times longer than that seen in other Themisto species ( T. japonica $6.5 \mathrm{~h}$, Yamashita et 
al. 1985; T. gaudichaudi between $7.5 \mathrm{~h}$ and $8.1 \mathrm{~h}$, Pakhomov \& Perissinotto 1996, Froneman et al. 2000). In these studies, the DT was determined using a linear regression to describe the decrease in SFI with time, which may account for the difference; had we used the same method, DT would have been estimated at ca. 5 to $6 \mathrm{~h}$. However, the decrease in SFI in our study did not match exactly the increase in DI and we judged it more prudent to combine both indices in our determination of DT. The effect of some factors, such as temperature, the number of prey in the stomach, prey size and the influence of activity during feeding, may all affect the digestion time. Some of these factors have been reported to influence the value of DT in mysids (Cartes et al. 2001) and chaetognaths (Tönnesson \& Tiselius 2005), but not in decapods (Maynou \& Cartes 1998). The effects of these factors on our estimate of DT are not clear and could not be assessed with our approach. Ingestion of prey before sunrise or during daytime would result in an overestimation of DT, and consequently the underestimation of daily ingestion rates. DT was inversely related to water temperature in mysids (Chipps 1998) and it is generally accepted that metabolic rates of fish and aquatic invertebrates are proportional to temperature (Karamushko \& Shatunovskij 1993). The fact that T. libellula lives in the CIL at temperatures varying between -1 and $+3^{\circ} \mathrm{C}$ may explain its high estimated DT. Moreover, our estimate was close to the DT maxima found for Euphausia superba and Boreomysis arctica (equal to $10 \mathrm{~h}$ and $9 \mathrm{~h}$, respectively), which also live in cold water (Pakhomov \& Perissinotto 1997, Cartes \& Maynou 2001).

In the present study, the DIR of Themisto libellula was estimated using 2 different approaches, and a pronounced variability in the results was observed. The DIR on mesozooplankton and macrozooplankton globally was twice as high when obtained from the calculation of feeding rates for individual prey types (16.39 and $16.82 \%$ body DM d ${ }^{-1}$ for the LSLE and NWGSL, respectively, in 2003), compared with the DIR estimated from the SFI (7.19 and 6.32\% body DM d ${ }^{-1}$ for the same regions and year). These variations seem to be related to the 2 models founded on the Bajkov's (1935) equation. Most studies that used Bajkov's method were conducted using prey frequency (Froneman \& Pakhomov 1998). Less common were those that used biomass, or an index of biomass, as the SFI (Pakhomov \& Perissinotto 1996, Froneman et al. 2000). Over the course of digestion, the number of prey accountable by direct observation does not change much until digestion is well advanced, unlike the prey biomass, which changes progressively. This could explain part of the large difference seen between the 2 methods. In this case, the DIR determined from the SFI method will be underestimated.
With regard to Themisto libellula, the in situ DIR estimated for zooplankton when using the SFI method was in reasonable agreement with those for T. gaudichaudi calculated with the same method $(6.3 \%$ of body dry mass, Pakhomov \& Perissinotto 1996; and 11.5 and $19.8 \%$ for both offshore and inshore locations, Froneman et al. 2000) and for T. japonica calculated from in vitro experiments $(6.6 \%$ of body dry mass, Ikeda \& Shiga 1999). The DIR from the feeding rate method (second approach), estimated at 16.4 and $16.8 \%$ for the LSLE and the NWGSL, respectively, corresponded to in vitro daily rations. The DIR obtained by in vitro incubations for $T$. gaudichaudi ranged from 8.5 to $21.8 \%$ (Pakhomov \& Perissinotto 1996) and from 15.4 to $24.2 \%$ for T. japonica (Yamashita et al. 1985). The wide range in the DIR of $T$. gaudichaudi may be attributable to differences in its estimated DT, as well as differences in seawater temperature. The degree of overlap between the vertical distribution of predator and prey may also explain some of the disparities between these estimates (Gibbons \& Painting 1992). In the second approach, incomplete ingestion of prey may cause bias or lower the precision of the DIR (Båmstedt \& Karlson 1998). We minimized the effect of this problem by not using the average biomass of adult euphausiids in reconstructing their contribution to the diet. Instead, we used the maximum stomach fullness observed in $T$. libellula that contained euphausiids (5.10 mg dry wt) and assumed that this was the maximum possible contribution to ingested biomass. Thus, the bias of incomplete prey ingestion may be negligible in our study. Themisto libellula is, therefore, seen as an active predator that exhibits a high DIR.

Very little is currently known about the rates of daily food consumption by Themisto libellula. The only daily ingestion rate available for this species was estimated by Auel \& Werner (2003) in the Greenland Sea from predation experiments on Calanus copepods and respiration measurements. The DIR in their study was evaluated at $1.9 \%$ of body dry mass (Auel \& Werner 2003). This must be compared with our DIR for all prey types taken together, which varied between 7.65 $\left(\mathrm{DIR}_{1}\right)$ and $16.61 \%\left(\mathrm{DIR}_{2}\right)$ in the present study, depending on method and region. The different results seen in these studies are difficult to interpret because a variety of methods were used. However, our ingestion rates were determined in situ whereas that of Auel \& Werner (2003) came from predation experiments and may be influenced by several factors, such as bottle effects or light intensity, which may affect prey or predator behaviour or prey availability. Furthermore, Auel \& Werner (2003) did not exclude the possibility that stress during the catch could have led to a reduced feeding activity. 


\section{Predation impact}

Considering the high biomass and daily ingestion rates of Themisto libellula in the SLMS, effects on the local zooplankton communities may be expected. As estimated by the first method, the daily predation impact of $T$. libellula on the zooplankton standing stock never exceeded $0.8 \%$. On the other hand, the predation impact estimated using the second method was higher and accounted for 1.8 and $0.5 \%$ of the zooplankton standing stock for the LSLE and the NWGSL, respectively. The predation impact is a function of both prey and predator biomass and the daily ingestion rate. Hence, all of the biases associated with DIR as well as abundance estimates may have an effect on this impact. In the SFI approach, predation impact should be regarded as an underestimate as the DIR was underestimated. Therefore, the impact of $T$. libellula predation may lie between these 2 estimates.

The predation impact of Themisto libellula in the SLMS might appear insignificant over the whole of the zooplankton community. Nevertheless, our predation estimate is much greater than that of Auel \& Werner (2003) in the Greenland Sea, who estimated that $T$. libellula removed only $0.03 \%$ of the mesozooplankton standing stock per day. The differing results could be related to differences in the abundance of T. libellula and in copepod biomass in the GSL and the Greenland Sea. The mean abundance of $T$. libellula varied between $1.5 \times 10^{-2}$ and $4.3 \times 10^{-2}$ ind. $\mathrm{m}^{-3}$ in the Greenland Sea and between $4.2 \times 10^{-2}$ and $11.1 \times 10^{-2}$ ind. $\mathrm{m}^{-3}$ in the LSLE and the NWGSL in 1998, 2003 and 2004 . This discrepancy is probably not enough to justify such a difference between the predation impacts; rather, it may be due to the difference in the daily rations (see previous discussion sub-section, 'Daily ration') and to the degree of overlap between the vertical distributions of hyperiid amphipods and their prey. Predation impacts that have been determined for other hyperiid amphipods are similar to those obtained in the present study. In South Georgia, Pakhomov \& Perissinotto (1996) revealed that the maximum predation impact of the Antarctic congener T. gaudichaudi was $2.1 \%$ of the total mesozooplankton standing stock when examined at its highest density $\left(1.5\right.$ ind. $\mathrm{m}^{-3}$ corresponding to $2.8 \mathrm{~g} \mathrm{DM} \mathrm{m}^{-2}$ ). The predation impact we estimated for the LSLE with the second approach is close to this result, even if the biomass of T. libellula was lower than that of $T$. gaudichaudi $\left(1.25 \mathrm{~g} \mathrm{DM} \mathrm{m}^{-2}\right)$. When the abundance of $T$. gaudichaudi in the Prince Edward Archipelago was low $\left(<0.2\right.$ ind. $\left.\mathrm{m}^{-3}\right)$, the predation impact of $T$. gaudichaudi never exceeded $0.2 \%$ of the mesozooplankton biomass (Froneman et al. 2000). The difference in the abundance of $T$. gaudichaudi in these latter studies reflected their variation in predation pressure (Froneman et al. 2000). Nevertheless, for the same zooplankton biomass and with a low predator biomass, $T$. libellula had almost the same predation impact as $T$. gaudichaudi; thus, T. libellula seems to exert a higher predation pressure than T. gaudichaudi. In the Oyashio region (western subarctic Pacific Ocean), predation impacts of $T$. pacifica and $T$. japonica on zooplankton biomass never exceeded 0.11 and $0.06 \%$, respectively (Yamada \& Ikeda 2006). These estimates are lower than our results, which may be attributable to differences in amphipod biomasses or in their daily rations.

To date, predation pressure has only been examined for the mesozooplanktonic community and there are no reports of the predation impact of Themisto spp. on copepod species. As a result, it is difficult to compare the estimated predation impacts in the SLMS with other regions. Nevertheless, the second method used in this study probably constitutes the best method to assess the predation impact of T. libellula on its prey. As predation impact on a prey depends on its relative biomass as a function of the predator's biomass, predation impact was more important on Calanus finmarchicus CVI-F and CVI-M and on Euchaeta norvegica than on $C$. finmarchicus $C V$, despite the fact that the greatest DIR was observed for the latter.

Themisto libellula is known to form dense swarms like T. gaudichaudi (Vinogradov 1999) and, thus, is able to reach very high densities (Eiane \& Daase 2002). Under such conditions, the potential impact of their predation may be substantial. Thus, T. libellula plays an important ecological role in the SLMS, exerting a significant control on the mesozooplanktonic populations, and more specifically, on Calanus finmarchicus and Euchaeta norvegica. The predation impact of $T$. libellula may be cyclical, undergoing seasonal variations, with higher or lower predation pressures at certain periods of the year. As a result, this species influences the trophic structure of the SLMS. Likewise, due to its abundance and trophic level, these amphipods are significant participants in the carbon flux of the GSL. Because of the pronounced importance of mesozooplanktonic communities in the food chain, T. libellula thus provides a key link between pelagic secondary production and higher trophic levels, including fishes and mammals, and fisheries productivity in the SLMS.

Acknowledgements. This study is a contribution to the Canadian Department of Fisheries and Ocean's (DFO) Ecosystem Research Initiative and was supported by DFO. The able technical contributions of J.-F. St-Pierre, P. Joly, J.-P. Allard and numerous other DFO personnel toward the collection of BIONESS data are gratefully acknowledged. We also thank L. Devine for helping to improve the quality of the text. 


\section{LITERATURE CITED}

Auel H, Werner I (2003) Feeding, respiration and life history of the hyperiid amphipod Themisto libellula in the arctic marginal ice zone of the Greenland Sea. J Exp Mar Biol Ecol 296:183-197

Auel H, Harjes M, da Rocha R, Stubing D, Hagen W (2002) Lipid biomarkers indicate different ecological niches and trophic relationships of the arctic hyperiid amphipods Themisto abyssorum and T. libellula. Polar Biol 25:374-383

Bajkov AD (1935) How to estimate the daily food consumption of fish under natural conditions. Trans Am Fish Soc 65: 288-289

Båmstedt U, Karlson K (1998) Euphausiid predation on copepods in coastal waters of the Northeast Atlantic. Mar Ecol Prog Ser 172:149-168

Bousfield EL (1951) Pelagic amphipoda of the Belle Isle Strait region. J Fish Res Board Can 8:134-163

- Cartes JE, Maynou F (2001) Trophodynamics of the deepwater suprabenthic mysid Boreomysis arctica in the Catalan Sea (western Mediterranean). Mar Ecol Prog Ser 211: $225-234$

- Cartes JE, Maynou F, Morales-Nin B, Massuti E, Moranta J (2001) Trophic structure of a bathyal benthopelagic boundary layer community south of the Balearic Islands (southwestern Mediterranean). Mar Ecol Prog Ser 215:23-35

Chipps SR (1998) Temperature-dependent consumption and gut-residence time in the opossum shrimp Mysis relicta. J Plankton Res 20:2401-2411

Dalpadado P (2002) Inter-specific variations in distribution, abundance and possible life-cycle patterns of Themisto spp. (Amphipoda) in the Barents Sea. Polar Biol 25: 656-666

Dalpadado P, Borkner N, Bogstad B, Mehl S (2001) Distribution of Themisto (Amphipoda) spp. in the Barents Sea and predator-prey interactions. ICES J Mar Sci 58:876-895

- Darbyson E, Swain DP, Chabot D, Castonguay M (2003) Diel variation in feeding rate and prey composition of herring and mackerel in the southern Gulf of St Lawrence. J Fish Biol 63:1235-1257

> Dempson JB, Shears M, Bloom M (2002) Spatial and temporal variability in the diet of anadromous arctic charr, Salvelinus alpinus, in northern Labrador. Environ Biol Fishes 64: $49-62$

Dunbar MJ (1946) On Themisto libellula in Baffin Island coastal waters. J Fish Res Board Can 6:419-434

> Dunbar MJ (1957) The determinants of production in northern seas: a study of the biology of Themisto libellula Mandt. Can J Zool 35:797-819

Eiane K, Daase M (2002) Observations of mass mortality of Themisto libellula (Amphipoda, Hyperidae). Polar Biol 25: 396-398

Falk-Petersen S, Sargent JR, Tande KS (1987) Lipid composition of zooplankton in relation to the sub-arctic food web. Polar Biol 8:115-120

Fortier M, Fortier L, Hattori H, Saito H, Legendre L (2001) Visual predators and the diel vertical migration of copepods under arctic sea ice during the midnight sun. J Plankton Res 23:1263-1278

Froneman PW, Pakhomov EA (1998) Trophic importance of the chaetognaths Eukrohnia hamata and Sagitta gazellae in the pelagic system of the Prince Edward Islands (Southern Ocean). Polar Biol 19:242-249

- Froneman PW, Pakhomov EA, Treasure A (2000) Trophic importance of the hyperiid amphipod, Themisto gaudichaudi, in the Prince Edward Archipelago (Southern Ocean) ecosystem. Polar Biol 23:429-436
Gibbons MJ, Painting SJ (1992) The effects and implications of container volume on clearance rates of the ambush entangling predator Pleurobranchia pileus (Ctenophora: Tentaculata). J Exp Mar Biol Ecol 163:199-208

Harvey M, Galbraith PS, Descroix A (2008) Vertical distribution and diel migration of macrozooplankton in the St. Lawrence marine system (Canada) in relation with the cold intermediate layer thermal properties. Prog Oceanogr doi:10.1016/j.pocean.2008.09.001

Harvey M, St. Pierre JF, Devine L, Gagné A, Gagnon Y, Beaulieu MF (2004) Oceanographic conditions in the Estuary and the Gulf of St. Lawrence during 2003: zooplankton. Fish Oceans Can Can Sci Advis Secretariat Res Doc 2004/080

Harvey M, St. Pierre JF, Devine L, Gagné A, Gagnon Y, Beaulieu MF (2005) Oceanographic conditions in the Estuary and the Gulf of St. Lawrence during 2004: zooplankton. Fish Oceans Can Can Sci Advis Secretariat Res Doc 2005/043

Hoffer SA (1971) Some aspects of the biology of Parathemisto (Amphipoda: Hyperiidea) from the Gulf of St. Lawrence. MSc thesis, McGill University, Montreal

Huntsman AG, Baily WB, Hachey HB (1954) The general oceanography of the Strait of Belle Isle. J Fish Res Board Can 11:198-260

Ikeda T, Shiga N (1999) Production, metabolism and production/biomass (P/B) ratio of Themisto japonica (Crustacea: Amphipoda) in Toyama Bay, southern Japan Sea. J Plankton Res 21:299-308

Kane JE (1963) Observation on the moulting and feeding of a hyperiid amphipod. Crustaceana 6:129-132

Karamushko LI, Shatunovskij MI (1993) Quantitative regularities of temperature effect on the rate of energy metabolism in Gadus morhua, Anarhichas lupus and Pleuronectes platessa. Vopr Ikhtiol 33:111-120

> Koszteyn J, Timofeev S, Weslawski JM, Malinga B (1995) Size structure of Themisto abyssorum Boeck and Themisto libellula (Mandt) populations in European arctic seas. Polar Biol 15:85-92

Lowry LF, Frost KJ (1984) Foods and feeding of bowhead whales in western and northern Alaska. Sci Rep Cetacean Res 35:1-16

> Maynou F, Cartes JE (1998) Daily ration estimates and comparative study of food consumption in nine species of deep-water decapod crustaceans of the NW Mediterranean. Mar Ecol Prog Ser 171:221-231

Nielssen KT, Haug T, Potelov V, Timoshenko YK (1995) Feeding habits of harp seals (Phoca groenlandica) during early summer and autumn in the northern Barents Sea. Polar Biol 15:485-493

Pakhomov EA, Perissinotto R (1996) Trophodynamics of the hyperiid amphipod Themisto gaudichaudi in the South Georgia region during late austral summer. Mar Ecol Prog Ser 134:91-100

> Pakhomov EA, Perissinotto R (1997) Mesozooplankton community structure and grazing impact in the region of the Subtropical Convergence south of Africa. J Plankton Res 19:675-691

Pedersen CE, Falk K (2001) Chick diet of dovekies Alle alle in northwest Greenland. Polar Biol 24:53-58

Percy JA (1993a) Energy consumption and metabolism during starvation in the arctic hyperiid amphipod Themisto libellula Mandt. Polar Biol 13:549-555

Percy JA (1993b) Reproduction and growth of the arctic hyperiid amphipod Themisto libellula Mandt. Polar Biol 13:131-139

Percy JA, Fife FJ (1993) Macrozooplankton, particularly spe- 
cies of Themisto (Amphipoda, Hyperiidea), and temperature, salinity and density data collected in eastern Hudson Strait in 1987-88. Can Data Rep Fish Aquat Sci 905, Ottawa > Plourde S, Dodson JJ, Runge JA, Therriault JC (2002) Spatial and temporal variations in copepod community structure in the lower St. Lawrence Estuary, Canada. Mar Ecol Prog Ser 230:211-224

R Development Core Team (2006) R: a language and environment for statistical computing. R Foundation for Statistical Computing, Vienna, www.R-project.org

Sameoto DD (1988) Feeding of lantern fish Benthosema glaciale off the Nova Scotia Shelf. Mar Ecol Prog Ser 44: 113-129

Sameoto DD, Jaroszynski LO (1973) Distribution of euphausiid scattering layers in the Gulf of St. Lawrence Estuary. Fish Res Board Can Tech Rep 430, Ottawa

Sheader M, Evans F (1975) Feeding and gut structure of Parathemisto gaudichaudi (Guerin) (Amphipoda, Hyperiidea). J Mar Biol Assoc UK 55:641-656

Tönnesson K, Tiselius P (2005) Diet of the chaetognaths Sagitta setosa and $S$. elegans in relation to prey abundance and vertical distribution. Mar Ecol Prog Ser 289: $177-190$

Editorial responsibility: Matthias Seaman,

Oldendorf/Luhe, Germany
Vinogradov GM (1999) Deep-sea near-bottom swarms of pelagic amphipods Themisto: observations from submersibles. Sarsia 84:465-467

Wood S (2005) mgcv: GAMs with GCV smoothness estimation and GAMMs by REML/PQL. R package version 1.3-7, R Foundation for Statistical Computing, Vienna

Yamada Y, Ikeda T (2006) Production, metabolism and trophic importance of four pelagic amphipods in the Oyashio region, western subarctic Pacific. Mar Ecol Prog Ser 308: 155-163

Yamashita Y, Aoyama T, Kitagawa D (1984) Laboratory studies of predation by the hyperiid amphipod Parathemisto japonica on larvae of the Japanese sand-eel Ammodytes personatus. Bull Jpn Soc Sci Fish 50:1089-1093

Yamashita Y, Kitagawa D, Aoyama T (1985) A field study of predation of the hyperiid amphipod Parathemisto japonica on larvae of the Japanese sand eel Ammodytes personatus. Bull Jpn Soc Sci Fish 51:1599-1607

Zakardjian B, Runge JA, Plourde S, Gratton Y (1999) A biophysical model of the interaction between vertical migration of crustacean zooplankton and circulation in the lower St. Lawrence Estuary. Can J Fish Aquat Sci 56: 2420-2432

Submitted: June 20, 2008; Accepted: September 1, 2008 Proofs received from author(s): December 16, 2008 